Anales de Geografía de la Universidad Complutense ISSN: 0211-9803

http://dx.doi.org/10.5209/AGUC.57726

\title{
¿Desarrollo rural o desarrollo de territorios rurales dinámicos? La contribución a los desequilibrios territoriales por parte de los Programas de Desarrollo en el sur de España, Andalucía ${ }^{1}$
}

\author{
José Antonio Cañete Pérez ${ }^{2}$; Eugenio Cejudo García ${ }^{3}$; Francisco Navarro Valverde ${ }^{4}$ \\ Recibido: 28 de octubre del 2016 / Enviado a evaluar: 14 de enero del 2017/ Aceptado: 24 de mayo del 2017
}

Resumen. Los efectos territoriales que han tenido los Programas de Desarrollo Rural en el sur de Europa, concretamente en la región de Andalucía (España), han sido variados. Partiendo del máximo nivel de desagregación de los proyectos ejecutados en el marco de la iniciativas LEADER y PRODER se realiza un análisis de un conjunto de variables sintéticas a nivel de proyecto, municipio y grupo de desarrollo rural con el objeto de evaluar hasta qué grado dichos programas han coadyuvado al desarrollo de las zonas más desfavorecidas de la región, o por el contrario han incrementado las diferencias preexistentes. La investigación realizada ha permitido constatar como en Andalucía la mayor parte de las iniciativas se han concentrado en las zonas más dinámicas, las más pobladas, en las que existía un tejido empresarial que ha sido capaz de aprovechar el acceso a la financiación europea, lo que ha reforzado su papel de liderazgo frente a las zonas más deprimidas con escaso capital social y empresarial.

Palabras clave: Andalucía; Desarrollo Rural; Desequilibrio Territorial.

[en] Rural development or development of dynamic rural territories? The contribution to territorial imbalances by the Development Programas in southern Spain, Andalusia

\footnotetext{
Abstract. The territorial effects that have the Rural Development Programmes in Southern Europe, in the region of Andalusia (Spain) have been varied. Based on the maximum level of disaggregation of the approved projects under the LEADER and PRODER initiatives, it has been analized a set of synthetic variables at the project level, municipalities and local action groups in order to assess to what extent have

1 Este trabajo se ha realizado en el marco del proyecto de investigación "Programas de desarrollo y cambio rural en la Unión Europea: gobernanza, resultados y lecciones a compartir 2007-13" financiado por el Ministerio de Economía y Competitividad español dentro de su Programa de Excelencia, CSO2014-56223-P.

2 Departamento de Geografía. Humana. Universidad de Granada

E-mail: joseaca@ugr.es

3 Departamento de Geografía. Humana. Universidad de Granada E-mail: cejudo@ugr.es

4 Departamento de Geografía. Humana. Universidad de Granada E-mail: favalver@ugr.es
} 
performed such programmes to the development of the most disadvantaged areas of the region, or in the opposite way, have increased the pre)existing differences. The investigation has revealed in the region of Andalusia that most of the initiatives have focused on the most dynamic areas, the most populated, in which there was a business sector that has been able to take advantage of access to european funding, which has reinforced its leadership role against the most depressed areas with little social and business capital.

Keywords: Andalucia; Rural Development; Territorial imbalance

\section{[fr] Développement rural ou développement de territoires ruraux dynamiques? La contribution aux déséquilibres territoriaux par le Programme de développement dans le sud de l'Espagne, en Andalousie}

Résumé. Les effets territoriaux qui ont été les programmes de développement rural en Europe du Sud, dans la région d'Andalousie (Espagne) ont été mitigés. Basé sur le niveau maximum de désagrégation des projets mis en œuvre dans le cadre des initiatives LEADER et PRODER une analyse d'un ensemble de variables synthétiques au niveau du projet, la municipalité et le groupe de développement rural afin de l'évaluer est fait dans quelle mesure ces programmes ont contribué au développement des zones les plus défavorisées de la région, ou au contraire ont augmenté les différences préexistantes.L'enquête a révélé que, en Andalousie la plupart des initiatives se sont concentrées sur les zones les plus dynamiques, les plus peuplées, où il y avait un réseau d'entreprise qui a été en mesure de profiter de l'accès au financement européen, qui il a renforcé son rôle de chef de file contre les zones les plus défavorisées avec peu de capital social et des affaires.

Mots clés: Andalousie, développement rural, Déséquilibre territorial

Cómo citar. Cañete Pérez, J.A., Cejudo García, E. y Navarro Valverde, F. (2017): ¿Desarrollo rral o desarrollo de territorios rurales dinámicos? La contribución a los desequilibrios territoriales por parte de los Programas de Desarrollo en el sur de España, Andalucía. Anales de Geografía de la Universidad Complutense, 37(2), 265-295.

Sumario. 1. Introducción. 2. Fuentes y metodología. 3. Resultados. 3.1. La inversión y subvención en Andalucía. 3.2. La distribución de la inversión y subvención a nivel GDR. 3.3. Los proyectos con mayor inversión/subvención y con menor inversión. 3.4. La inversión y subvención por habitante. 3.5. Los municipios con mayor inversión/subvención. 3.6. Los municipios con nula inversión y menor inversión. 3.7. Los proyectos ejecutados por municipios y la inversión por proyecto. 3.8. El empleo. 3.9. La confirmación de nuestra hipótesis. 4. Conclusiones. 5. Bibliografía. 6. Normativa.

\section{Introducción}

La Iniciativa Comunitaria LEADER (Liaisons Entre Actions de Developpement de l'Économie Rurale) es el programa emblemático dentro de la política de desarrollo rural de la Unión Europea, a pesar de su modesta aportación de recursos financieros. Durante los últimos 25 años ha tratado de reducir las disparidades territoriales entre las áreas urbanas y las rurales, entre territorios rurales dinámicos y deprimidos. Esta iniciativa está basada en los siguientes principios: enfoque ascendente, participación en la toma de decisiones, paternariados público-privados que constituyen Grupos de Desarrollo Rural (GDR), cooperación interterritorial, desarrollo rural integrado, 
utilización de los recursos endógenos y perspectiva territorial, promoción de la innovación y, por último, diversificación económica. Esta iniciativa ha contribuido a incorporar nuevos principios a las recientes teorías del desarrollo neo-endógeno, combinando y complementando los enfoques ascendente y descendente, las fuerzas endógenas y exógenas, la participación y las relaciones internas y externas (Ray, 2006; Marsden, 2009), y los instrumentos de gobernanza y de gobierno. Visión del desarrollo rural en el que en última instancia lo que prima es la calidad de vida y la capacidad de llevar una vida digna (Castree et al., 2013). Como bien señala Guinjoan et al, (2016), el desarrollo de los espacios rurales debe sustentarse en un nuevo paradigma que supere visiones parciales y parta de una visión integradora en el que el desarrollo económico no puede separarse de las mejoras de las condiciones sociales, del mantenimiento del entorno físico que lo sustenta y en definitiva de la calidad de vida de sus habitantes.

Este estudio se centra en el análisis de uno los principios señalados anteriormente, el enfoque territorial, y dentro de éste, en uno de sus principales objetivos: el de reequilibrar, "permitir que poblaciones especialmente debilitadas o situadas en zonas del territorio en declive se beneficien también de las oportunidades planteadas" (Observatorio Europeo LEADER, 2001, 27). La hipótesis de este trabajo es, como se corroboró en anteriores estudios a escala local y comarcal en el caso de la provincia de Granada (Cejudo y Navarro, 2009; y Cejudo y Navarro, 2011), que la distribución de las inversiones en los PDR, en un ámbito regional, se concentra en los territorios rurales más dinámicos, y al contrario, el territorio rural profundo y más deprimido queda al margen de tales iniciativas emprendedoras. Se asiste, como se apreciará más adelante, a una distribución de sus inversiones desigual en el territorio, reforzando las disparidades en favor de los centros comarcales, ciudades medias y territorios más dinámicos, donde existe empresariado solvente, en detrimento de los municipios del rural profundo, coincidentes con los marginales de esta región.

El enfoque desde el que se aborda esta investigación es distinto al habitualmente estudiado por otros expertos centrados básicamente en aspectos relacionados con la creación de capital social y de procesos de gobernanza gracias a la constitución de partenariados público-privados en el contexto de estas Iniciativas. En la mayor parte de estos trabajos también se advierte la ausencia de implicación y/o participación real de los ciudadanos (Plaza, 2005; Böcher, 2008; Dargan y Shucksmith, 2008; Buciega, 2012; Esparcia, 2014; Esparcia y Escribano, 2012: 237; Augustyn y Nemes, 2014; Martínez et al., 2015; Bosworth et al., 2016), y el reforzamiento de las estructuras de poder a favor de determinados lobbies económicos y políticos en detrimento de determinados grupos sociales que quedan marginados de ellas (Osti, 2000; Shortall, 2008; Nardone et al., 2010; Gardner, 2011; y Navarro et al., 2014), incluso en términos de género en relación con el empoderamiento de la mujer y de la gobernanza, especialmente en los territorios del rural profundo y montano (Cassellas et al., 2013), en el que la progresiva y mayor educación y formación les está permitiendo asumir retos y proyectos innovadores en el contexto del mundo rural. Dicho de otro modo, "la postura que apoya que la educación y la formación fueron para las mujeres rurales 
un elemento de desarraigo y desapego del medio rural y, en definitiva, de abandono del mismo ${ }^{5}$, ahora se revierte porque precisamente la educación y la formación se convierten en factores indispensables para construir las nuevas identidades rurales femeninas" (Porto et al., 2015: 403).

También, otros estudios denuncian que la administración, sobre todo la regional, ha dificultado y obstaculizado un mejor funcionamiento de los GDR al intervenir en la toma de decisiones y al burocratizar excesivamente la gestión, dando lugar a una sobrecarga de trabajo del equipo técnico $\mathrm{y}$, consiguientemente, a una menor dedicación a tareas de animación en aquellos lugares con menor tejido de empresarios y de iniciativas (Navarro et al., 2016). En otras ocasiones, la pervivencia de fuertes localismos y el relativo desconocimiento de las actuaciones de los GDR terminan propiciando que la población identifique a los ediles locales y al gobierno regional como responsables y artífices de los problemas y soluciones de los territorios, tal y como señala Llorente y Martín (2010) en la Comunidad Autónoma de Castilla y León.

Por otra parte, se puede considerar que la temática de este estudio dispone de una gran actualidad por varios motivos, más allá del hecho de la necesidad de, como señala GATER $(2015,19)$, "para extraer las mejores enseñanzas de la experiencia pasada sería necesaria una valoración más precisa de los periodos precedentes al que ahora finaliza (antes de 2007) y aprender de las aportaciones positivas, pero también manteniendo la necesaria capacidad crítica respecto de las posibles deficiencias, y aprender de ambos tipos de aportaciones". En primer lugar, los recientes estudios que tratan de explicar los factores que hacen a los territorios rurales más resilientes, entendido esto como la capacidad que tienen éstos de responder a la crisis, destacando algunos de ellos las prácticas de desarrollo neo-endógeno (Cheshire et al., 2015; Labianca et al, 2016), la existencia de partenariados público-privados constituidos como GDR (Martínez et al., 2015), una adecuada gestión de las ayudas al desarrollo rural, la capacidad institucional y la gobernanza, además del propio sector agrario, sector refugio y absolvedor de desempleados (Sánchez, et al., 2014) o la importancia que pudieran tener el cobro de prestaciones de desempleo agrario propias de nuestra región, como el Subsidio de Desempleo Agrario o la Renta Agraria (Cejudo et al., 2016). Y en segundo lugar, las perspectivas existentes ante un nuevo periodo de programación que llevan a la Comisión Europea a replantearse varias cuestiones de la política de desarrollo rural, de manera específica, y de desarrollo regional, de manera global. Así, el Reglamento 1303/2013 establece, en su artículo 35, como uno de los tres retos prioritarios para las Estrategias de Desarrollo Local participativo, de la próxima iniciativa LEADER para el periodo 2015)2020, "la mejora de los servicios públicos y la calidad de vida, que ayude a paliar el déficit de oportunidades respecto del medio urbano, con especial atención a la población más desfavorecida y en riesgo de exclusión". Por tanto, de forma implícita se consideran los problemas de los

\footnotetext{
${ }^{5}$ La denominada "huida ilustrada" (Camarero, 2009; Ministerio de Medio Ambiente, y Medio Rural y Marino, 2011)
} 
espacios rurales marginales, a través de la inclusión social, la reducción de la pobreza y el desarrollo económico en las zonas rurales (Esparcia y Escribano, 2012; De Rubertis y Belliggiano, 2016). Además, se asiste también a una necesidad de replanteamiento de las relaciones entre lo rural y lo urbano, de lo recomendable de incluir las market towns en las áreas LEADER y en los proyectos derivados de esta iniciativa por la gran interdependencia que poseen con sus territorios rurales cercanos (Bosworth et al, 2015), y que conlleva una cooperación entre áreas rurales y urbanas. Y por último, la necesidad de reconsiderar por parte de los PDR las disparidades y diversidades intrarrurales (Saraceno, 2013).

\section{Fuentes y metodología}

Las fuentes de información utilizadas han sido, específicamente, dos. Por un lado, la relación de proyectos ejecutados durante el periodo 2002)2008 proporcionada por la Dirección General de Desarrollo Territorial de la Junta de Andalucía a través de la aplicación informática SEGGES.

El estudio se ha centrado en las actuaciones ejecutadas dentro de la Iniciativa LEADER + y PRODER-Andalucía (PRODER-A). En el primer caso tanto en su Eje 1 como 2.1; en el segundo, PRODER-A se concretó en la inclusión, dentro del Programa Operativo Integrado de Andalucía (POIA), de dos medidas en su Eje 7: la 7.55 sobre desarrollo endógeno de zonas rurales en el ámbito agrario: diversificación agraria, financiada por el FEOGA-O, y la 7.59 sobre desarrollo endógeno de zonas rurales no ligado a actividades agrarias, financiada por el FEDER.

El tratamiento de la información se ha realizado a nivel de expediente lo que permite conocer, con el mayor nivel de detalle posible, parámetros como: medida a la que se acoge cada proyecto, inversión total comprobada, subvención certificada, inversión privada certificada, empleos creados y consolidados (diferenciando hombres, mujeres y menores de 30 años), tipo de beneficiario, municipio en el que se ejecuta, etc. Ello se ha concretado en una relación de 9.502 registros de los que se ejecutaron 8.221. De ellos, se han podido diferenciar $6.750(82,11 \%)$ en los que la inversión realizada se produce en un municipio concreto mientras que en 1.471 $(17,89 \%)$ el territorio beneficiado es colectivo apareciendo en el apartado "municipio de ejecución" con la denominación de "varios municipios" y que, mayoritariamente, hacen referencia a proyectos promovidos por los diferentes GDR o a consorcios de municipios, etc. A estos hay que añadir los proyectos fallidos, aprobados pero no ejecutados que son 1.281.

Esta información específica se ha complementado con otra de carácter estadístico que ha permitido la elaboración de indicadores básicos y correlaciones estadísticas. Esta información tanto demográfica como económica ha sido obtenida de la aplicación web del Sistema de Información Multiterritorial de Andalucía (SIMA) del Instituto de Estadística y Cartografía de la Junta de Andalucía. De este mismo 
organismo son los ámbitos administrativos municipales que dan soporte a la cartografía, y por agregación de estos a los ámbitos de los GDR.

Las variables analizadas se han incorporado a un Sistema de Información Geográfica, utilizando para ello el ARCGIS 10.2. Las salidas planimétricas corresponden a tal aplicación informática.

Hay que señalar especialmente, que dada la amplitud de la comunidad autónoma de Andalucía se ha planteado el análisis territorial a dos niveles: de una parte a nivel municipal, descendiendo en algunos aspectos incluso al proyecto aprobado, y de otro, a nivel de GDR, siendo éste el que consideramos más adecuado para el análisis territorial. De igual modo, debe señalarse que se ha primado la visualidad de los resultados, ya que es a través de la cartografía elaborada como se aprecian las variaciones territoriales.

\section{Resultados}

Antes exponer los resultados obtenidos, conviene reseñar los fondos que Andalucía ha recibido a través de los Programas de Desarrollo Rural en los últimos años. El gasto público nacional pasó de los 8.382,1M€ en 1994-1999 a 15.119M€ en 20002006, 7.213,8 en 2007-2013 y 9.089,9 M€ para 2014-2020. Ello se tradujo en que Andalucía percibió $1.321,2 ; 2.521,2 ; 1.881,7$ y $2.092,7$ M€, respectivamente, lo equivale al 16, 17, 26 y $23 \%$ del total nacional siendo así su máxima perceptora y ello a pesar de ser, casi, la única CC.AA. perdedora (200 M€) en el nuevo reparto. La cicatera e intransigente disciplinaria financiera europea y los muy discutibles criterios aplicados por nuestro Ministerio en los menguantes fondos europeos explican el balance nacional y andaluz descrito.

Por otro lado, hemos de señalar que, para el periodo estudiado, PRODER-A dispuso de más de 212M€ de gasto público (190,36 para la medida 7.55 y 22,05 para la 7,59$)$, la mayor parte de los fondos fueron europeos $(70 \%)$, un $21 \%$ autonómicos y el resto nacionales. Por su parte, la Iniciativa LEADER +, concebida por la Junta como complementaria de PRODER, tuvo una aportación financiera pública de $129,7 \mathrm{M} €$ de los que dos terceras partes provienen de la UE y el resto son nacionales.

Es evidente, con estos datos, que los fondos ligados a estas dos actuaciones tienen una significación muy reducida si la contemplamos en el marco de la financiación global que recibe el desarrollo rural multifuncional del que tanto se habla y se aboga; en efecto sólo suponen el 13,55\% del total de sus fondos. Ahora bien, este incontrovertible hecho no debería hacernos olvidar que estamos hablando de las dos iniciativas más emblemáticas de la política de desarrollo rural europea por lo que aportan en términos cualitativos, metodológicos, de filosofía a la hora de ejecutar este nuevo desarrollo para los territorios rurales de la UE. Es por este motivo por lo que se pone el acento en su estudio, más allá de su significación cuantitativa, en relación con su capacidad o no de alterar/propiciar las dinámicas imperantes en estos territorios. 


\subsection{La inversión y subvención en Andalucía}

En una primera aproximación sobre la repercusión de los Programas LEADER y PRODER en Andalucía en el periodo 2002-2008, lo primero que se constata es que su incidencia territorial ha sido muy extensa, ya que los GDR constituidos abarcan la mayor parte del territorio andaluz. Han quedado fuera de estos programas sólo los entornos más próximos a las capitales andaluzas (Cádiz, Huelva, Sevilla, Córdoba, Málaga, Almería, Granada y Jaén) y sectores del litoral mediterráneo de las provincias de Cádiz, Málaga, Granada y Almería.

La inversión total realizada fue de poco más de 928 millones de $€(M €)$ de los cuales 347,64 millones (el 37,4\%) son los que se corresponden con las subvenciones concedidas y 580,47 millones (el 62,6\%) con la inversión privada realizada. Si se tiene en cuenta, a su vez, en estas cifras globales del conjunto de Andalucía, el tipo de destinatario y el empleo creado se acotan un poco más estos valores de conjunto. De este total de proyectos en poco más de una cuarta parte (el 25,13\%) ejercen como promotores los propios ayuntamientos (2.066 en valores absolutos) con inversiones que superan los $113 \mathrm{M} €$, correspondiendo más del $65 \%$ a subvención. Otro número importante lo conforman los promovidos por los propios GDR con 1.355 proyectos (el $16,48 \%$ del total) y una inversión de algo más de $104 \mathrm{M} €$, en su mayor parte correspondientes a subvenciones ( $88 \mathrm{M} €$ ) el $85 \%$ del total invertido.

Otra característica de este tipo de proyectos de "promoción pública" es el escaso empleo que generan, ya que para el conjunto de Andalucía y el periodo contemplado los ayuntamientos sólo han acumulado el 5,31\% de los empleos creados y los GDR el $1,64 \%$. Resulta evidente, a la luz de estas cifras, que en la promoción pública su objetivo principal no es la creación de empleo sino más bien la subsanación de deficiencias en materia de equipamientos e infraestructuras en el caso de los ayuntamientos, o la difusión-gestión en el caso de los GDR.

Si se suman los proyectos promovidos por los ayuntamientos y los propios GDR andaluces, estos suponen el $41,61 \%$ del total, siendo la subvención concedida a sus proyectos de $162 \mathrm{M} €$. Cantidad esta que representa casi la mitad de todas las subvenciones concedidas, concretamente el $46,6 \%$ del total.

De los datos anteriores se deduce claramente la importancia que "los promotores públicos" han tenido en la gestión e impulso del desarrollo rural andaluz. Aunque es indudable que las labores de promoción)difusión de las actividades del GDR, así como la dotación de infraestructuras y equipamientos por parte de los ayuntamientos influyen en la mejora de la calidad de vida de los habitantes de estos espacios rurales, $\mathrm{y}$ por ende en la permanencia de los mismos en estos espacios, no son pocos los autores (Hortelano y Martín, 1999; Navarro y Larrubia, 2000; Pillet y Santos, 2008) que cuestionan que el excesivo peso de este tipo de proyectos desvirtúan una de sus principales finalidades, el desarrollo económico, la mejora del tejido productivo y el acceso a la innovación y la diversificación empresarial.

Resulta evidente que la existencia de un buen equipamiento deportivo o cultural mejora la calidad de vida; y si para su construcción se recurre a este tipo de fondos es 
una opción correcta, pero quizás cabe preguntarse, también, si a través de estos recursos financieros se enmascaran unas cifras globales, que en el fondo, en una parte muy importante de las mismas, vienen a suplir la falta de inversión en las áreas rurales de otras administraciones en materias que son de su competencia, ya sean autonómica, provincial o estatal. En definitiva, los ayuntamientos como otro agente más del territorio acometen, ante la ausencia de iniciativa privada, lícitamente proyectos de interés social para cubrir necesidades colectivas locales que sus exiguos presupuestos impiden (Alario y Baraja, 2006: 290-1).

En cualquier caso, estas cifras globales a nivel de Andalucía, no hacen más que confirmar a nivel de comunidad autónoma lo que ya se había apuntado en otros estudios en ámbitos más reducidos como la provincia de Granada (Cejudo y Navarro, 2009) sobre la debilidad del tejido productivo regional y la concentración de los proyectos bien en los que hemos denominado "promotores públicos" bien en las sociedades mercantiles (en su mayor parte constituidas con anterioridad). Efectivamente, las empresas (ya sean anónimas o limitadas) llevan a cabo el 18,51\% de los proyectos (1.522), pero en cambio concentran el 38,90\% de la inversión comprobada (algo más de $361 \mathrm{M} €$ ) y casi la mitad de la inversión privada (algo más de 279 M€ que suponen el 48,15\% del total invertido). La importancia de estas sociedades empresariales en relación con el empleo es evidente, pues concentran el $49,37 \%$ del empleo creado en el periodo analizado y el $46,56 \%$ del empleo consolidado. En relación con el empleo joven las cifras se sitúan en el mismo rango con un 50,78\% (2.424 absolutos) del total de esta categoría. De nuevo, los valores medios del conjunto de Andalucía están en la tónica de lo detectado en ámbitos provinciales (Cejudo y Navarro, 2012).

\subsection{La distribución de la inversión y subvención a nivel GDR}

Si bien las cifras globales anteriormente expuestas nos ofrecen una idea de la proporción existente entre inversión total comprobada y subvención, estos datos, a su vez, presentan un comportamiento territorial muy dispar. Tal y como se puede constatar en el cuadro $\mathrm{n}^{\mathrm{o}} 1$, son los GDR asentados en el sector occidental de Andalucía (Guadalquivir Medio, Vega de Sevilla, Guadajoz o Aljarafe) los que presentan cifras de inversión mayores, superando los $20 \mathrm{M} €$, y porcentajes sobre el total de lo invertido en Andalucía próximos al 3\%. 
Cuadro 1. Inversión y subvención según GDR y provincias en $€$ y \% sobre el total

\begin{tabular}{|c|c|c|c|c|c|c|}
\hline GDR & $\begin{array}{c}\text { Iminexxing } \\
\text { CEmpremadn }\end{array}$ & $\begin{array}{l}\text { Sivmmine in n } \\
\text { Certifix adn }\end{array}$ & 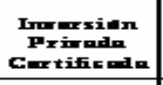 & 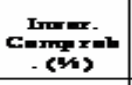 & $\begin{array}{c}\text { Shllu- } \\
\text { Centif } \\
\text { (Yis) }\end{array}$ & 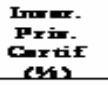 \\
\hline 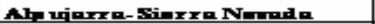 & 17.229 .051 & 6352.201 & 10.076 .770 & 1.06 & 1. ב. & 1.07 \\
\hline Lrmente Alminierre & 16.163 .049 & 6512.073 & 0.650 .961 & 1.34 & 1. 13 & 1.6.6 \\
\hline 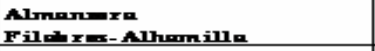 & $\begin{array}{l}14.019 .654 \\
14.759 .914 \\
\end{array}$ & $\begin{array}{r}563.193 \\
6025.613 \\
\end{array}$ & $\begin{array}{l}0.256 .461 \\
0.734 .302 \\
\end{array}$ & $\begin{array}{r}1.6 \\
1.59\end{array}$ & $\begin{array}{l}1.09 \\
1.33 \\
\end{array}$ & $\begin{array}{r}1.42 \\
1.5 \\
\end{array}$ \\
\hline Vinln & 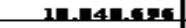 & 605.310 & 11.053.310 & $2 . n 3$ & 1.0. & 2.06 \\
\hline ATMRRIA & 87.820 .369 & 32.348 .483 & 49.471 .880 & 282 & $9.3 x$ & 252 \\
\hline simpendecalix & 22.246 .650 & 7003.555 & 14.343.n.5. & 2.4 & 2.27 & 2.47 \\
\hline Litexal an In Jonin & $20.62 n .015$ & 6.91.01日 & 13.763 .063 & 2.22 & 1.97 & 2.37 \\
\hline Alcmentenlmx & 20.410 .705 & 2327.670 & 13.0n.3.117 & 2.2 & 2.11 & 2.25 \\
\hline Inxex & 12.053 .352 & 6250.056 & 6.654 .496 & 1.4 & 1. 11 & 1.15 \\
\hline CADrz & 76.239 .682 & 28.399 .108 & 47.848 .575 & $22 x$ & $8, x>$ & \&24 \\
\hline Mrdin Gradnlawix & 27.032 .241 & 0233.062 & 10.39日. 379 & 2,91 & 2.37 & 3.24 \\
\hline 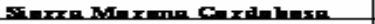 & $17.02 n .018$ & $n=70.45 n$ & -0.041 .450 & 1.02 & 2.55 & 1.54 \\
\hline Pedxex hex & 21.336 .072 & 3.032 .522 & 14.304.350 & 2.3 & z.0z & 2.46 \\
\hline 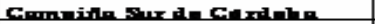 & 14.171 .102 & 6.62 .044 & $2.47 \times .110$ & 1.53 & 1.03 & 1.20 \\
\hline 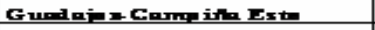 & 22.203 .233 & 6.434 .441 & $15.94 n .792$ & 2.4 & 1.55 & 2.73 \\
\hline Yallndel Alt Gundinth & 24.241 .116 & n20.6.5 & 16.037.44n & 2.61 & 2.35 & 2.76 \\
\hline Shlhlutixn Cexd-hen & 22.770 .354 & 6.64 .317 & 16.01日..037 & 2.45 & 1.02 & 2.37 \\
\hline CORTACRA & 149.655 .817 & 52.161 .242 & 97.494575 & 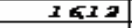 & 15 & 168 \\
\hline 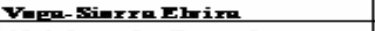 & 10.546.067 & $5=10.952$ & 12.335 .915 & $\mathbf{z}$ & 1.67 & 2.19 \\
\hline 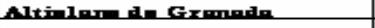 & 16.642 .962 & 6.421 .317 & 10.213 .575 & 1.70 & 1.5 & 1.76 \\
\hline Gurlix & 23.201 .30 & 11.161 .162 & 12.040 .626 & 2.5 & 3.21 & 2.07 \\
\hline Pnimnte Gxmolinn & 10.413 .172 & $0.04 n+21$ & 10.372 .300 & $2 . n$ & 2.5 & 1.72 \\
\hline Mentex de Gxmindn & 17.079.3.9. & 5.710 .516 & 11.36드. 23 & 1.04 & 1.64 & 1.56 \\
\hline Amrendin-Thmin & 10.373 .778 & 0.451 .555 & 11.022 .222 & 1.0. & 1.5 & 2.05 \\
\hline Axke Nexext do la Vere & 15.949 .621 & 5.773 .514 & 10.176.107 & 1.72 & 1.65 & 1.75 \\
\hline GRARIAIAA & 129.207 .524 & 50.377 .957 & 78.829 .567 & 1392 & $1<40$ & I고요 \\
\hline 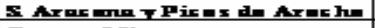 & 13.316 .790 & 3214.795 & 10.432 .004 & 1.91 & $\mathbf{2 . 1}$ & 1. \\
\hline Cunsa Millexn & $10.202 .4=6$ & 300.314 & 11.115 .732 & 1.9. & 2.04 & 1.91 \\
\hline Cendade de Humbe & 20.307 .965 & 6.627 .370 & 13.760 .107 & 2.2 & 1.91 & 2.37 \\
\hline Cextn Oxxidental & 19.050.939 & 39.400 .074 & 15.110 .05 & 2.05 & 1.13 & 2.6 \\
\hline 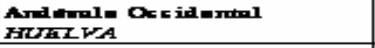 & $\begin{array}{r}10.154 .049 \\
93.520 .239 \\
\end{array}$ & $\begin{array}{r}7.302 .541 \\
32.727 .902 \\
\end{array}$ & $\begin{array}{l}10.371 .501 \\
68.798 .337\end{array}$ & $\begin{array}{r}1.90 \\
1008 \\
\end{array}$ & $\begin{array}{l}2.24 \\
9.42\end{array}$ & $\begin{array}{r}1.30 \\
x Q 48 \\
\end{array}$ \\
\hline simxinde somen & 13.510 .614 & 5057.554 & 2.642 .060 & 1.47 & 1.71 & 1.72 \\
\hline Ceninde de Jath & 12.649 .947 & 6.431 .729 & 6.210 .210 & 1.36 & 1. 15 & 1.07 \\
\hline simxn Maping & 17.071 .320 & 6.72 .175 & 11.012 .145 & 1.94 & 1. & 1.91 \\
\hline 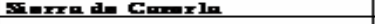 & 17.001.06. & 6.676 .060 & 11.125 .006 & 1.92 & 1.92 & 1.92 \\
\hline Simen She de Jonth & 21.452 .974 & 7373.151 & 14.01日2.n23 & 2.31 & 2.12 & 2.43 \\
\hline Cmmping Nete de Inth & 19.452 .00 & 7.756 .266 & 11.706 .542 & 2.1 & 2.23 & z.0z \\
\hline Inmme lox vallox & 23.020.054 & 6.94 .627 & $16.0 n 3.22 \mathrm{n}$ & $2.4 n$ & $z$ & 2.77 \\
\hline IAAR & 125.978 .385 & 48.027 .362 & 77.957 .023 & $x$ 조가 & $x \exists .8 x$ & $1 \geq \& 3$ \\
\hline Aminuth & 17.541 .004 & 6.051 .575 & 11.410 .410 & 1. & 1.74 & 10 \\
\hline Syxmin de Kende & 14.4.40.379: & 6336.064 & 0.144 .315 & 1.56 & 1. & 1.4 \\
\hline Yallmall Gimindexter & $16.114 .0 \mathrm{ng}$ & 0.453 .722 & 1.650 .237 & 1.74 & 1.5 & 1.5 \\
\hline 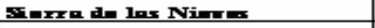 & 15.051.035 & 7321.550 & 3.729 .406 & 1.62 & 2.11 & 1.3. \\
\hline Gumalthen & 16.3nn.265 & 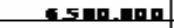 & 0.790 .456 & 1.75 & 1. & 1.6. \\
\hline Antramin & 17.005.021 & 6331.141 & 11.474 .60 & 1.92 & 1. $=2$ & 1.9 \\
\hline Thxxituxin Nmxnxinnml & 16.012 .140 & 5 n34.0nz & 10.247 .2319 & 1.73 & 1.5 & 1.77 \\
\hline$M A T A E A$ & 113.454654 & 44919.873 & 68.534842 & $x 222$ & 12.92 & $x$ I. $8 x$ \\
\hline Shxxmin Shmente & 20.111 .007 & 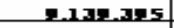 & 10.072 .512 & 2.17 & $2.6 x$ & בחת \\
\hline Alaxnf-Dentmm & 22.49 .905 & -413.020 & $14.2=4.963$ & 2.45 & 2.42 & 2.46 \\
\hline 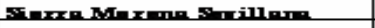 & 15.421 .326 & 6.120 .154 & 0.600 .472 & 1.5 & 1.5 & $1.4 n$ \\
\hline 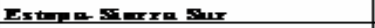 & 12.761.日. & 6.704 .055 & 6.057 .775 & 1.30 & 1.53 & 1.04 \\
\hline Gxmingendn silln & 26.315 .057 & 6.621 .051 & 10.723 .905 & 2.14 & 1.0 & 3.41 \\
\hline 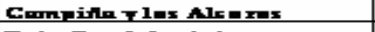 & 21.945 .56 & 3039.270 & 14.906.291 & 2.36 & 2.02 & 2.57 \\
\hline In min G andnlmuim ix & 21.010 .554 & 7221.010 & 13. 150.615 & 2.27 & 2.n & 2.30 \\
\hline Cexx 1ex ale 1n F1ma & 17.025.373 & 6.739 .60 & 11.015.6.67 & 1.92 & 1.94 & 1.91 \\
\hline SFFTICA & I S 8.240 .44 & 587.000 .080 & 99.540 .333 & 17.05 & 1689 & 17.15 \\
\hline TOTAI_GDK & 920.113 .070 & 347.411 .947 & 500.475 .131 & 100 & | & 100 \\
\hline
\end{tabular}

Fuente: Consejería de Agricultura, Pesca y Desarrollo Rural. Junta de Andalucía. Elaboración propia.

A nivel provincial son Córdoba y Sevilla con un 16,12\% y 17,05\%, respectivamente, las que concentran los valores más altos. Por el contrario, las cifras provinciales más bajas se encuentran en Almería (cuyos GDR invierten el 8,82\% del total) y Cádiz (con el 8,21\%). A nivel de GDR los valores más reducidos se encuentran en el ámbito de Jerez con un 1,40\% del total, el Condado de Jaén con un 
$1,36 \%$, y Estepa-Sierra Sur con un 1,38\%. Las variaciones territoriales quedan expresadas de una forma más evidente en la figura $\mathrm{n}^{\circ} 1$, observando una cierta concentración de las inversiones mayores en torno al eje del Guadalquivir, en las provincias de Córdoba y Sevilla. De igual modo, las inversiones menores se concentrarían en la Sierra de Huelva y en los espacios montañosos de las provincias de Málaga, Granada, Jaén y Almería. No deja de ser significativo que en estos ámbitos se localicen precisamente las áreas con menores niveles de desarrollo económico de la Comunidad Autónoma.

Figura 1. Inversión Comprobada en los GDR de Andalucía (2002-08).

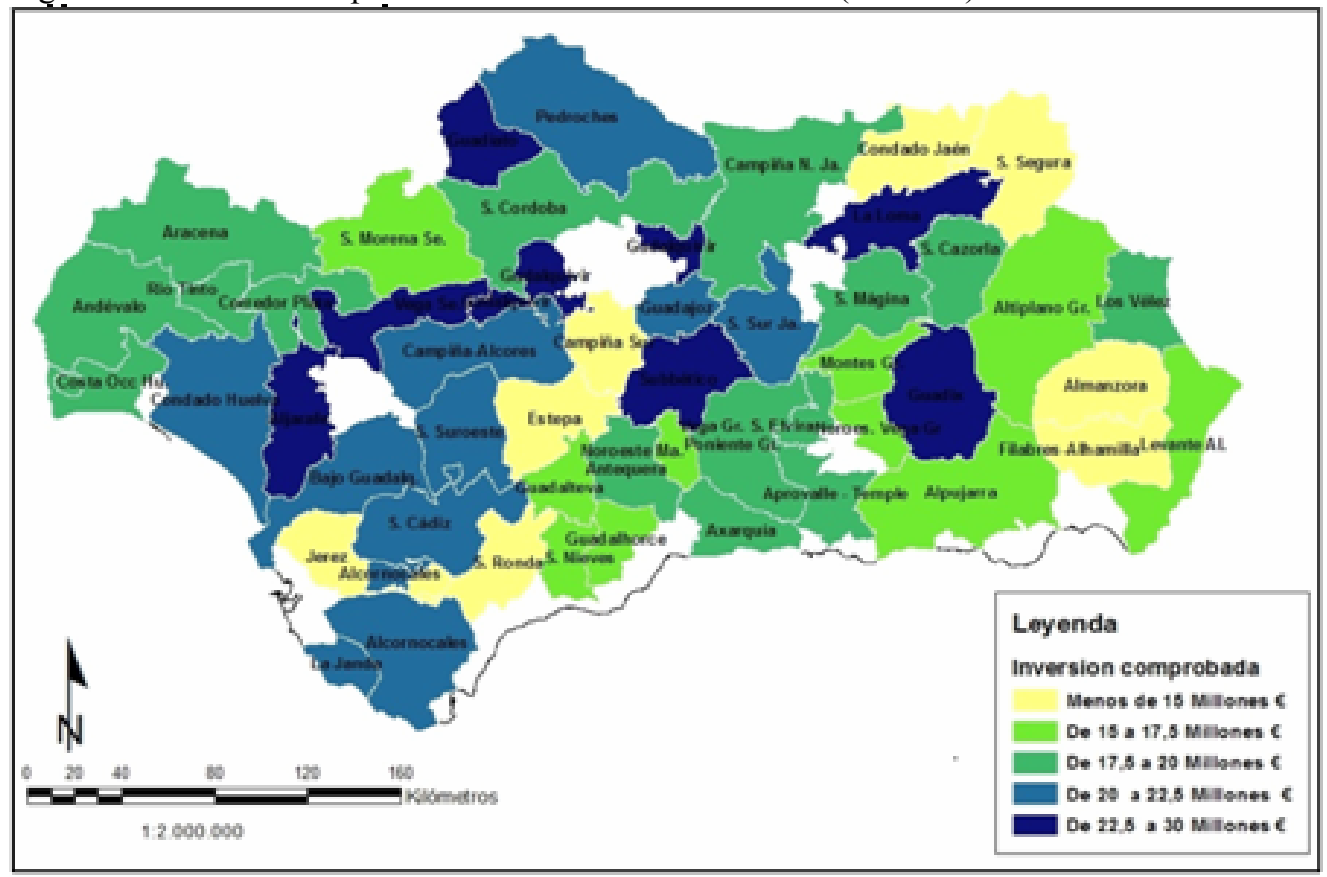

Fuente: Consejería de Agricultura, Pesca y Desarrollo Rural. Junta de Andalucía. Elaboración propia.

Los valores globales anteriores se ven matizados si se tiene en cuenta la subvención certificada (figura $\mathrm{n}^{\circ} 2$ ) pues en cifras absolutas la mayor parte de los GDR andaluces se sitúan entre los 6 y $8 \mathrm{M} €$, mientras los relativos (porcentaje sobre el total) presentan cifras entre el $1,75 \%$ y el $2,20 \%$. La clave de este comportamiento territorial se va a encontrar en la distribución de la inversión privada (figura $\mathrm{n}^{\mathrm{o}} 3$ ) y su comparación con la figura de inversión total certificada. Serán los GDR de las provincias de Córdoba y Sevilla los que presenten cifras absolutas superiores a los 13 M€ de inversión y, con cierta frecuencia, superiores a los 16 (Medio Guadalquivir, Guadajoz, Subbética Cordobesa, Gran Vega de Sevilla, o Alcores, entre otros). 
Figura 2. Subvención certificada en los GDR de Andalucía (2002-08)

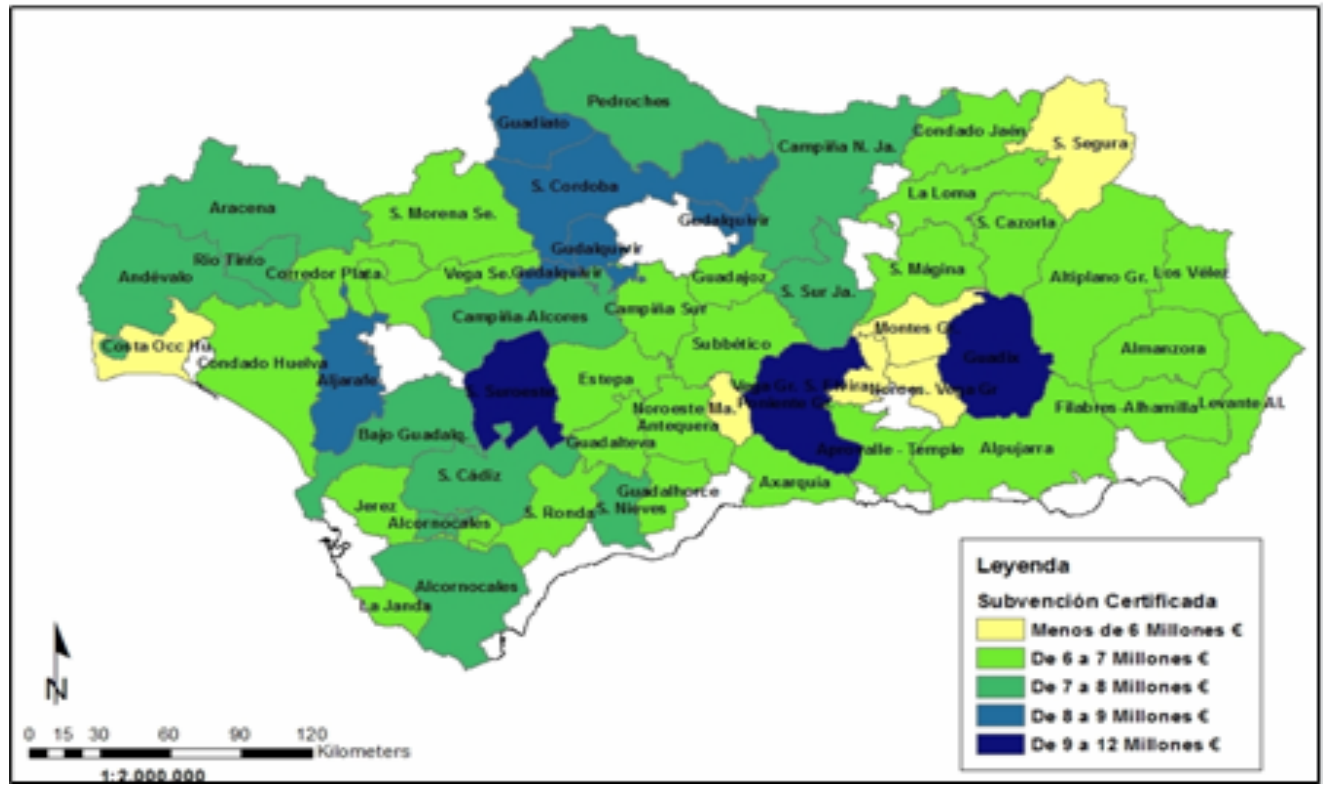

Fuente: Consejería de Agricultura, Pesca y Desarrollo Rural. Junta de Andalucía. Elaboración propia.

Figura 3. Inversión privada en los GDR de Andalucía (2002-08)

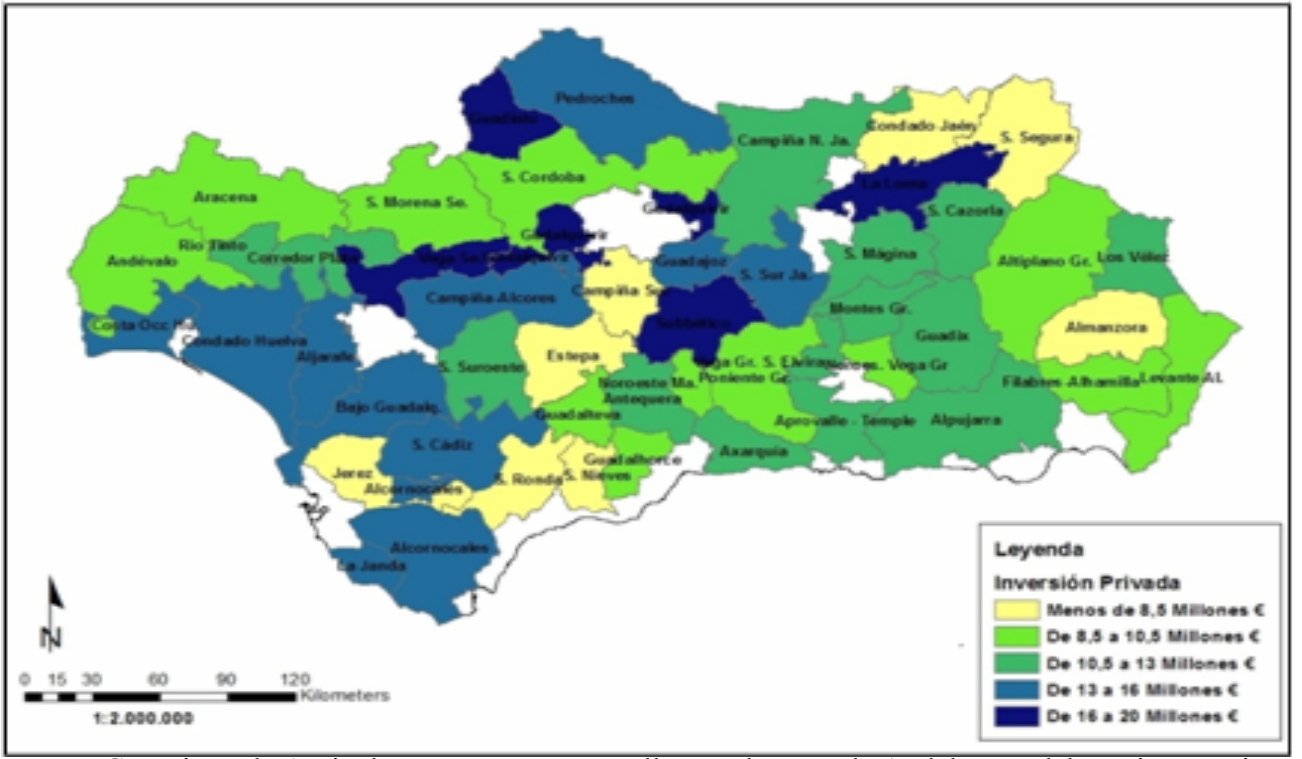

Fuente: Consejería de Agricultura, Pesca y Desarrollo Rural. Junta de Andalucía. Elaboración propia. 
¿Qué nos están diciendo estos datos a nivel de Andalucía? Que la inversión comprobada ha ido pareja a la inversión privada, existiendo una correlación entre ambas. O lo que es lo mismo, los programas LEADER y PRODER han tenido una mayor incidencia y peso allá donde ya existía un tejido empresarial capaz de invertir y, por tanto, de "aprovechar las subvenciones existentes" a nivel europeo. En estudios realizados para la provincia de Granada se ha podido demostrar dicha relación (Cejudo y Navarro, 2012).

\subsection{Los proyectos con mayor inversión/ subvención y con menor inversión}

El análisis a nivel de proyecto complementa la información anterior. Así se ha confeccionado el cuadro $\mathrm{n}^{\mathrm{o}} 2$, que recoge los 25 proyectos con mayor inversión total comprobada. De estos datos deben destacarse varios aspectos:

- Del total de 25 proyectos con mayor inversión 22 han sido llevados a cabo por sociedades mercantiles y 3 por asociaciones. Debe resaltarse, en este sentido, que no hay ningún proyecto desarrollado por un empresario autónomo.

- Espacialmente se ejecutan en municipios de todas las provincias, si bien el mayor número se concentra en Jaén con 6 proyectos. El tipo de proyecto más numeroso es el destinado al hospedaje ya sea en forma de hotel o alojamiento rural (13 proyectos), seguidos de las instalaciones asistenciales tipo centro geriátrico o atención a discapacitados (7 proyectos). Los proyectos comerciales/industriales son los menos representados.

- La cuantía máxima de los proyectos comprobados es de 3,4 M€ (Centro Geriátrico de Baena). La posición más baja de este "Top25" lo ocupa la Residencia Geriátrica de Chirivel con 1,3 M€ de inversión.

- La importancia de estas fuertes inversiones, mayoritariamente privadas, ya que la subvención concedida no suele superar el $10 \%$ del total, condiciona los resultados de los GDR. Si tomamos por ejemplo el caso de Guadajoz en Córdoba apreciamos que la inversión total es de 22,2 M€ y que sólo dos proyectos de los ejecutados en Baena (uno de hostelería y otro geriátrico) suponen el $22,9 \%$ de lo invertido en todo el GDR con un total de 186 proyectos. 
Cuadro 2. TOP25 Proyectos con mayor inversión comprobada

\begin{tabular}{|c|c|c|c|c|c|c|c|}
\hline Gupo & Tipo destin(1) & Prow. & Mune & Tipode Proyecto & rw. Domp. & stw. Certi. & Iner.Priv. \\
\hline GUADNG-CAUPIRA ET & 0.5 & CArtgen & Bunı & Po Ildunelı Grintrie! & $3.413 .932,53$ & $105.000,00$ & $3.371 .232,5 \mathrm{~g}$ \\
\hline ALCOAKXCALEI & 5.1 & CIJ & 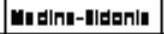 & |tat| & $3.455 .452,64$ & $150.000,00$ & $3.305 .452,64$ \\
\hline UUE:方ICA CORLOEAA & 5.1 & CArtugu & Gen & matuitril m anaeapa y grunite & $2.212 .125,4 \mathrm{~J}$ & $150.253,0 \mathrm{3}$ & $2.751 .172,40$ \\
\hline Lol vé & 0.7 & Alm Irin & Yola z-Püla & Ontra Atunelen Cieipueltuas & 2.7 a. $45 \mathrm{H}, \mathrm{gg}$ & $420.155,12$ & 2.322.5 23,17 \\
\hline GRA HVECA EEIEUILLA & 0.5 & In vill! & 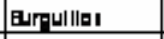 & $|t| a \mid$ & $2.471 .714,25$ & $100.000,00$ & $2.291 .714,25$ \\
\hline ALCORMOCALEI & 0.5 & C이 2 & Bnalup-Cial & tratal & $2.257 .901,40$ & $550.112,50$ & $1.707 .025,90$ \\
\hline MONTE EEGAARE & 0.5 & Grunuta & 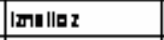 & Ra Ilanelı Gristrieı & $2.055 .75 \mathrm{gg}, 21$ & $200.000,00$ & $1.155 .7 \mathrm{Hg}, 2 \mathrm{I}$ \\
\hline LITORAL EELA JA HEA & 5.1 & C이 2 & Yupra la Ri. & $\mid$ tha & $2.033 .632,17$ & $250.000,00$ & $1.713 .632,17$ \\
\hline YALLEDE ALTOGUACAT & $T 0.5$ & CArtabu & $\theta \ln 12$ & malu i tri CImle! & 1.111.1155,17 & $250.000,00$ & $1.131 .1 \mathrm{Ag}, \mathrm{Ir}$ \\
\hline LA LOMAYLAI VILLAI & 0.7 & dun & الكاطا & Ontra Atunelen Dienpueltuas & 1.117.I23,EI & $222.128,11$ & 1.557.653,17 \\
\hline IERRAA EE CAZORLA & 0.5 & JuAn & runlu \{LI\} & tral & $1.001 .245,07$ & 100.00000 & $1.121 .945,07$ \\
\hline CA UPIRA KCRTE EEJA的 & 0.4 & Jun & Gralinı fLI! & Po Ildu nelı GrintrieI & $1.721 .502,10$ & $14.1 \mathrm{ar}, \mathrm{a} 1$ & $1.571 .504,57$ \\
\hline GLADNCZ-CA UPIRA ET & 70.5 & CArtagu & Bunı & 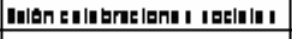 & $1.6 \mathrm{HH} .327, \mathrm{G5}$ & co.000,00 & $1.639 .327,65$ \\
\hline IERRA LECADE & 0.5 & C에이 2 & Artal ta in Ri. & Ontral al pratuete I hertieal & $1.674 .750,47$ & $122.14,45$ & $1.551 .211,01$ \\
\hline CONDDD DE HELVA & 0.5 & Hul I I & HnajeI & 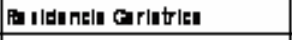 & $1.642 .413,08$ & $150.253,03$ & $1.492 .230,05$ \\
\hline DIERRA IUR CEJAG & 0.5 & Jutn & AlenII || fal| & $\mid$ tat & $1.528 .7 \mathrm{IA}, \mathrm{13}$ & $14.517,50$ & $1.415 .217 .3 \mathrm{~g}$ \\
\hline ALTIPLA WO DEGRANA DA & 0.5 & Grunudı & 20) & |t女a| & $1.5 \mathrm{gg} .7 \mathrm{Ad}, 0 \mathrm{~g}$ & $150.000,00$ & $1.44 .740,09$ \\
\hline IIERPA DE IEGURA & 0.5 & Jutn & Yarlai m un. & |tat| & $1.54 .515,21$ & $250.000,00$ & $1.2 \mathrm{HI.515,21}$ \\
\hline YEGA-IIRPA EVIRA & 0.5 & Grunutu & Palleral & |tat & $1.452 .211,6 \mathrm{Eg}$ & $115.275,15$ & $1.335 .942,14$ \\
\hline ALJARAE-DORANA & 0.2 & In villı & 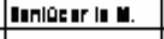 & 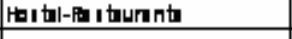 & $1.441 .456,3 \mathrm{~g}$ & $245.969,41$ & 1.191.495,al \\
\hline TERRITCRO MORORIETA L & 0.5 & manar & Arthl Eanı & Loundaria Indu i trial & 1.445.101,00 & $150.142,52$ & $1.2 \mathrm{g5} .931,31$ \\
\hline LA LOUA YLAI YILLAI & 0.5 & dutn & Bu a & $\mid$ the & $1.439 .511,45$ & $15.151,02$ & $1.350 .450,47$ \\
\hline 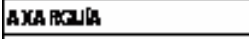 & 0.5 & Mulna & Yinusula & |tat | & $1.423 .105,14$ & $250.000,00$ & $1.173 .105,14$ \\
\hline YEGA-IIGRA EVIRA & 0.5 & Grunudu & Cousehinu & 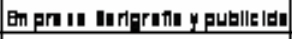 & $1.420 .300,30$ & $107.554,74$ & $1.312 .595,55$ \\
\hline LoIv自旦 & 0.7 & Alm IrII & Giru। & Po Ilaunelı GrintrleI & $1.94 .704,05$ & $330.117,14$ & $1.012 .5 \mathrm{g2}, \mathrm{r} 2$ \\
\hline
\end{tabular}

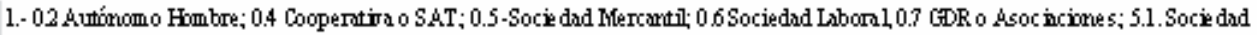
Mercomtil ( $+25 \%$ ioten).

Fuente: Consejería de Agricultura, Pesca y Desarrollo Rural. Junta de Andalucía.

El análisis de los 25 proyectos andaluces con mayor subvención concedida resulta, también, muy revelador en cuanto al tipo de promotor y la tipología de los proyectos. Sus características serían las siguientes:

- Predominio del promotor público, ya sean los propios GDR/asociaciones o los ayuntamientos. Solo en el municipio de Benalup-Casas Viejas aparece una sociedad mercantil para la construcción de un hotel entre los mayores beneficiarios de las subvenciones.

- Los proyectos con mayores cantidades subvencionadas, se destinan en gran medida a la dinamización y divulgación de actividades, con una fuerte presencia de diversos Centros de Interpretación o de Innovación de cada uno de los territorios. Asumiendo, como señalan Arcilla y López (2015: 161-162), que su distribución geográfica no ha sido la adecuada, con una planificación territorial, de gestión y mantenimiento, en muchos casos, errónea o inexistente 
fruto, demasiadas veces, de una sobrevaloración de su potencial turístico; no podemos olvidar que estos centros deben ser valorados no sólo desde la óptica de la rentabilidad económica sino también como espacios dinamizadores de la cultura y el territorio, lo que se ha venido en llamar "economía creativa", por su capacidad de estimular la creación de empleo y de promover un nuevo modelo económico, así como el desarrollo de ciudades y territorios. Esto supone la revalorización de la cultura y del capital cultura como importante recurso además de como factor de cohesión social y de aprendizaje colectivo (Caravaca y Otros, 2013)

- Son importantes, también, inversiones en materia de equipamientos, ya sea en forma de rehabilitación)restauración de elementos patrimoniales (Pósito de Loja), la construcción de guarderías (Nueva Cartaya), Residencias de la Tercera Edad (Santo Tomé) o de una piscina (La Rinconada).

- Los importes absolutos de las subvenciones oscilan entre los $770.000 €$ del Centro de Interpretación Itinerante del Patrimonio del GDR de Guadix (Granada) y los $300.000 €$ del Centro de Iniciativas Socieconómicas de Sierra Morena en el municipio de Obejo del GDR de la Sierra Morena Cordobesa.

- Se aprecia una fuerte variación en las subvenciones realizadas, pues mientras un número reducido de proyectos presentan cifras significativas, otros, la mayoría, registran valores muy bajos. Así por ejemplo los tres proyectos incluidos en el TOP 25 y que se ejecutan en el GDR de Guadix (Centro de Interpretación Itinerante del Patrimonio, Centro de Interpretación del Megalitismo y la Implantación de Sistemas de Calidad en Establecimientos Turísticos) con una subvención total de 1,65 M€ suponen el 14\% del total subvencionado para 191 proyectos ejecutados. Conviene recordar, no obstante, que en regiones como la andaluza, de Objetivo 1, la subvención en proyectos no productivos puede llegar al $100 \%$.

- Espacialmente no se aprecia ninguna concentración específica que justifique la distribución, por lo que habría que considerar que gran parte de las variaciones se deben al dinamismo que los propios GDR imprimen dentro de sus zonas de gestión.

Por último, debe señalarse que las mayores subvenciones concedidas son las asociadas a los propios gastos de funcionamiento de los GDR. Los proyectos con mayor inversión tienen su imagen inversa en los que presentan una menor inversión. Proyectos menores en los que predominan los cursos y talleres más variados, con inversiones totales que oscilan entre los 232 y los $828 €$ para estos 25 proyectos. En todos los casos los promotores son los propios ayuntamientos o asociaciones con una subvención que con frecuencia asume la totalidad del gasto de ejecución. 


\subsection{La inversión y subvención por habitante}

Tanto la distribución territorial de la inversión como subvención por habitante se encuentran muy condicionadas por la forma en la que se han ido constituyendo los GDR de Andalucía, mediante la adición de municipios espacialmente próximos, y que en la mayor parte de las ocasiones trataron de coincidir con anteriores identidades territoriales o comarcalizaciones (agraria, entre otras), siendo la suma de varias de ellas las que constituyen un GDR.

Los indicadores socioeconómicos de estos espacios permiten apreciar estas diferencias. De esta forma, frente a ámbitos con más de 250.000 habitantes como el del Bajo Guadalquivir en Sevilla, o que superan ampliamente los 100.000 habitantes ) Subbética de Córdoba, Campiña y Alcores, Vega de Sevilla, Condado y Costa de Huelva, Jerez, Campiña norte de Jaén, Campiña Sur de Córdoba, Vega de Granada, Axarquía de Málaga o Sierra de Cádiz) se encuentran otros que ni siquiera llegan a los 20.000 habitantes (Arco Noroeste de la Vega de Granada, Cuenca Minera de Huelva o Filabres).

Figura 4. La inversión por habitante año 2006 en los GDR de Andalucía (2002-08)

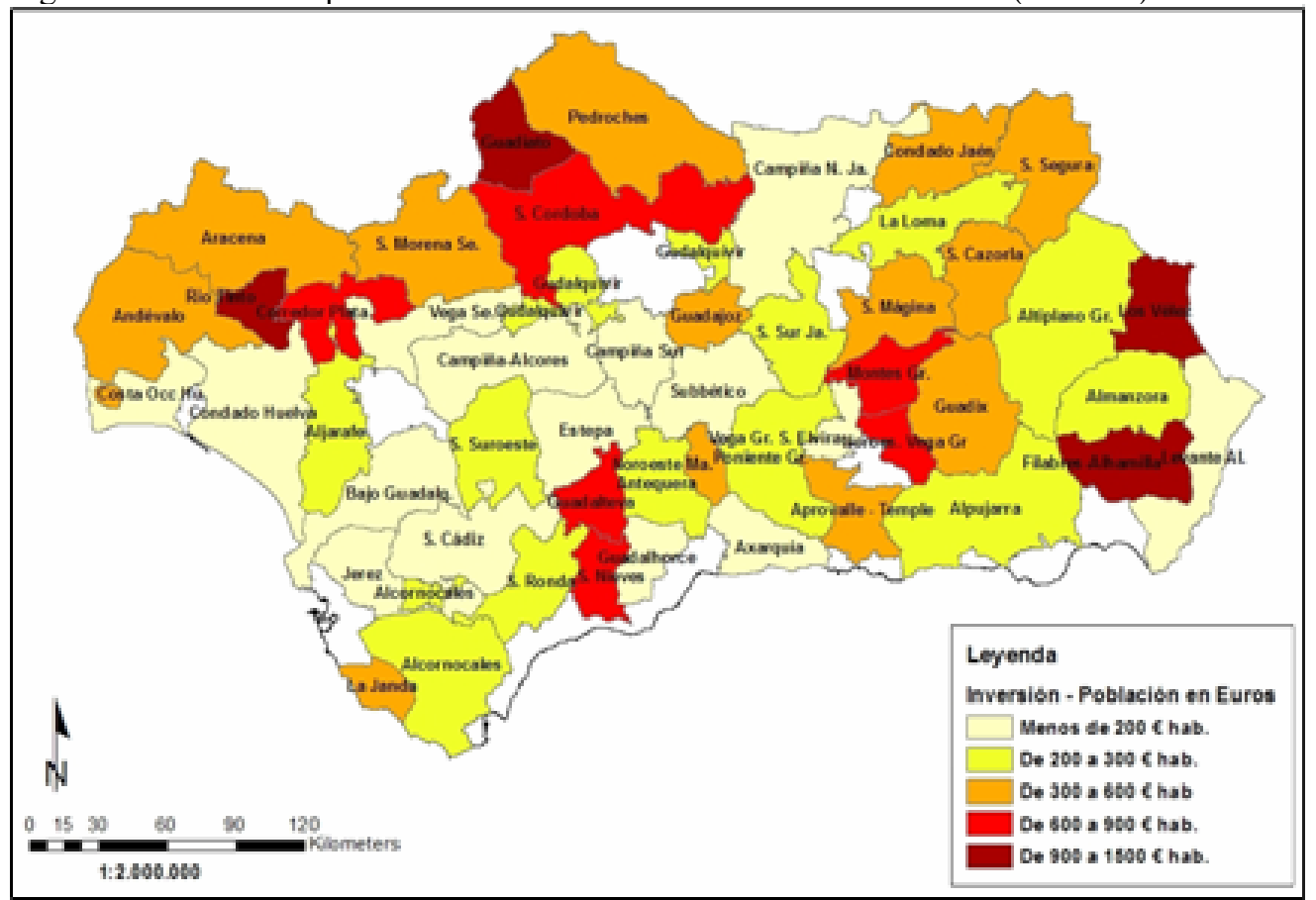

Fuente: Consejería de Agricultura, Pesca y Desarrollo Rural. Junta de Andalucía. Elaboración propia.

El ámbito con menor población es el de Los Vélez, con 12.576 habitantes en el año 2006 y 4 municipios. 
Los GDR que contienen una menor población serán los que, proporcionalmente, presenten la mayor inversión por habitante, por encima de los $1.000 € /$ habitante.

Por esta razón, la disparidad de tamaño superficial y demográfico de los distintos GDR, el análisis espacial de la Inversión Certificada/Habitante no ofrece unos resultados claros tal y como se puede comprobar en la figura $\mathrm{n}^{\mathrm{o}} 4$.

Así, serán los GDR localizados en las tierras bajas, campiña del Guadalquivir y zonas costeras (las más pobladas) las que presenten índices más bajos, mientras territorios menos poblados como las zonas serranas, con índices de densidad de población más bajas presentan valores más elevados.

\subsection{Los municipios con mayor inversión/subvención}

Para entender la dinámica andaluza de las inversiones en proyectos LEADER y PRODER, de nuevo es necesario descender al ámbito municipal para analizar las distribuciones espaciales de las inversiones y su reparto territorial. Para ello se han confeccionado sendos listados con los 50 municipios con mayor Inversión Certificada Total y mayor Subvención (figuras $n^{\circ} 5$ y 6 ).

Figura 5. TOP 50 Municipios mayor inversión de los GDR (2002-08)

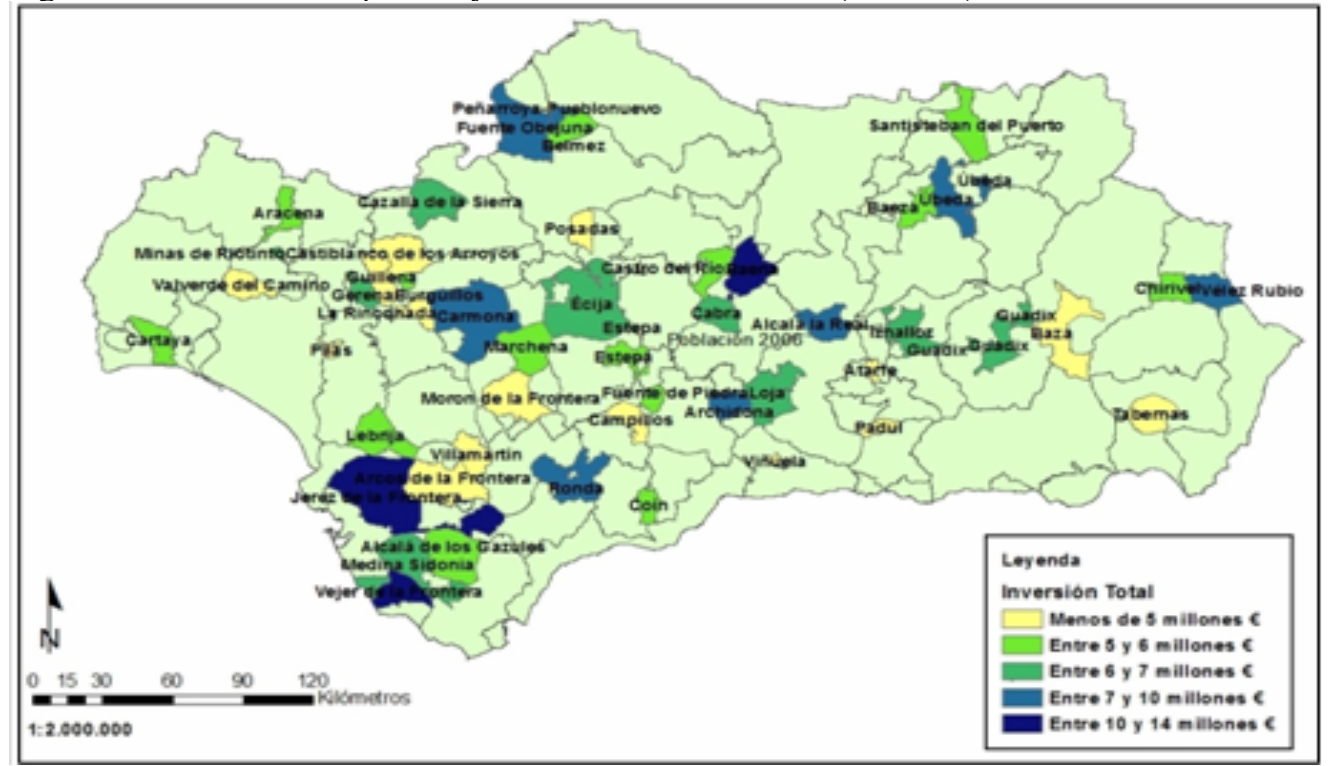

Fuente: Consejería de Agricultura, Pesca y Desarrollo Rural. Junta de Andalucía. Elaboración propia.

La figura confeccionada es muy clara en relación con la localización espacial de estos municipios. En primer lugar y ateniendo sólo a los incluidos en este "TOP 50" se aprecia una concentración en el eje del Guadalquivir, especialmente en el arco comprendido entre Jerez de la Frontera y Baena, con inversiones mayoritariamente 
superiores a los $6 \mathrm{M} €$. En segundo lugar destacan municipios que localizados en áreas serranas (Vélez Rubio, Peñarroya, Aracena) tienen un significativa función comarcal o concentran las mayores poblaciones dentro de su ámbito.

Esta idea, queda confirmada si se comparan los datos de esta figura con el que refleja la población de estos municipios (figura $\mathrm{n}^{\mathrm{o}} 6$ ).

Figura 6. Población en 2006 de municipios mayor inversión GDR (2002-08)

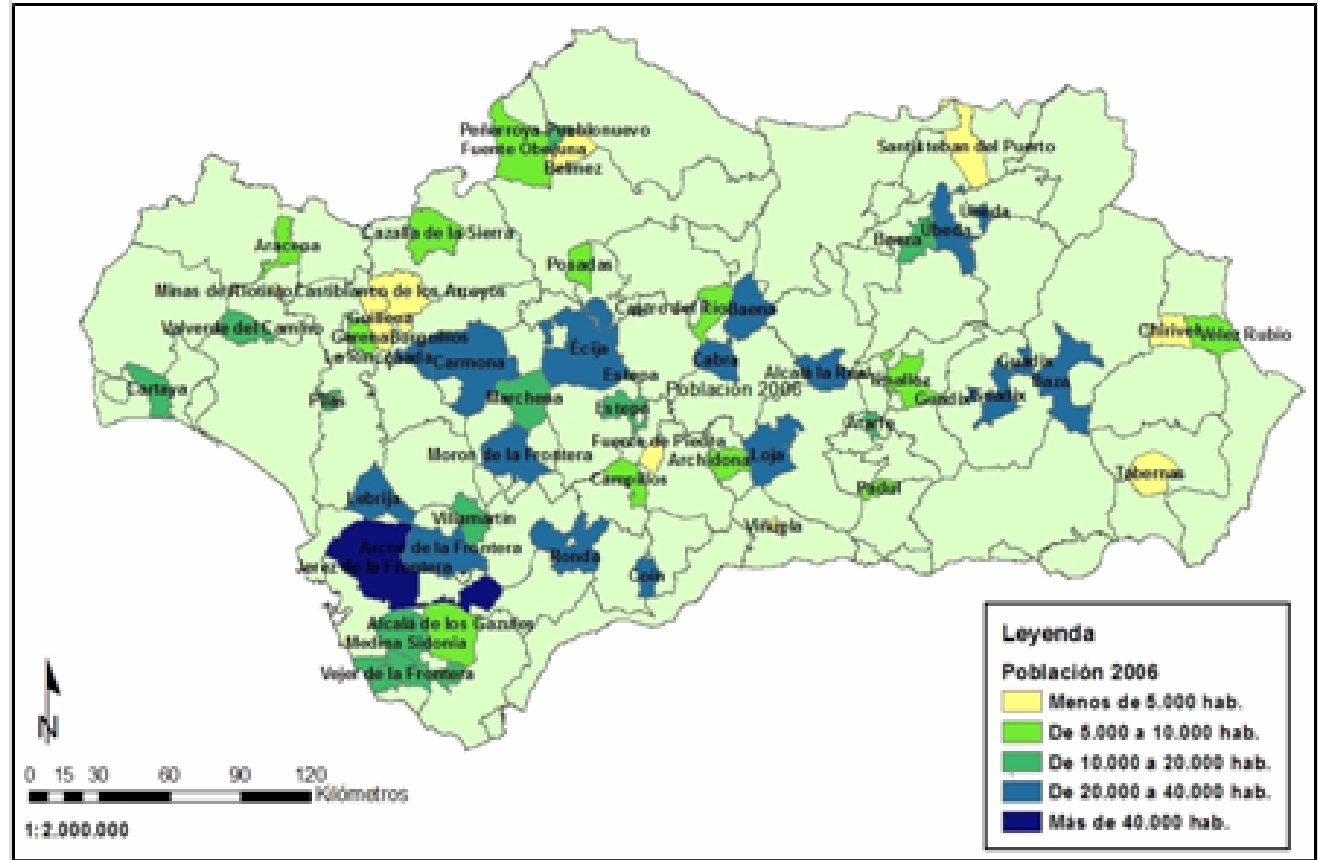

Fuente: Consejería de Agricultura, Pesca y Desarrollo Rural. Junta de Andalucía. Elaboración propia.

Efectivamente, los municipios que concentran la mayor inversión municipal son los que presentan poblaciones más elevadas, generalmente superiores a los 20.000 habitantes (Carmona, Écija, Cabra, Lebrija, Morón de la Frontera, Ronda, Guadix, Baza, Úbeda, Alcalá la Real, Arcos de la Frontera, etc.) y ejercen destacadas funciones comarcales. Se confirma así a nivel de Andalucía lo que ya apuntaban otros estudios sobre el tema (Cejudo y Navarro, 2012) cuando señalaban que los proyectos de desarrollo rural lejos de favorecer un reequilibrio territorial acentuaban las desigualdades existentes al concentrarse precisamente en los núcleos más dinámicos de Andalucía, donde ya existía un tejido empresarial previo.

Esta información se ve contrastada y complementada con la figura $\mathrm{n}^{0} 7$ en la que se recoge el TOP 50 de los municipios que han recibido mayores subvenciones. La pregunta resulta inevitable ¿son los mismos municipios que en el caso anterior? ¿Juegan el mismo papel territorial? 
Figura 7. Población en 2006 de municipios mayor subvención GDR (2002-08)

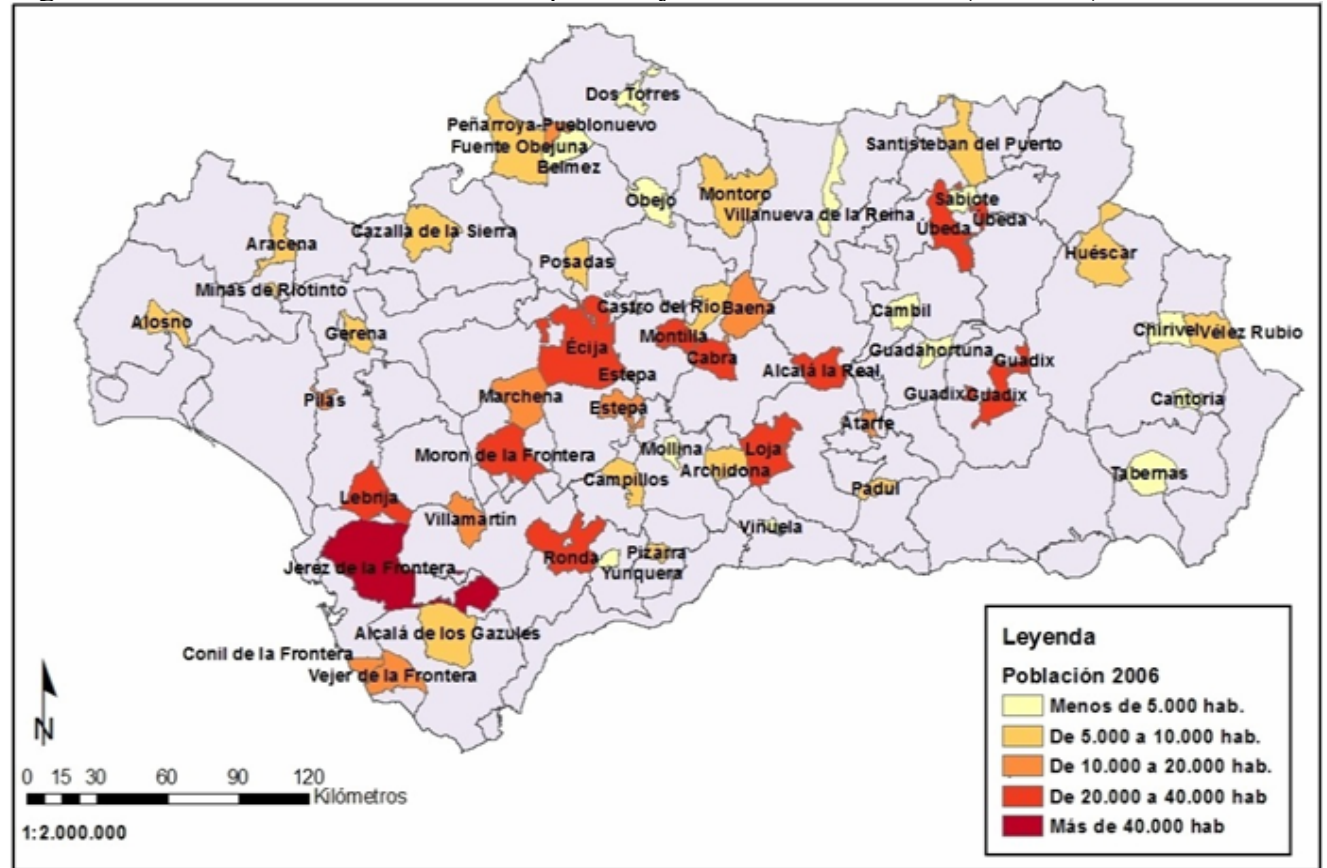

Fuente: Consejería de Agricultura, Pesca y Desarrollo Rural. Junta de Andalucía. Elaboración propia.

Aunque se aprecian ciertas similitudes entre los municipios con mayor inversión y mayor subvención (TOP 50), es posible observar diferencias en su distribución espacial. Es cierto que, en líneas generales coinciden, pues en ambos casos suelen corresponder con las cabeceras comarcales, con mayor población y, por tanto, con un dinamismo económico más claro. Es decir, tanto la inversión comprometida, como las subvenciones concedidas refuerzan ese papel comarcal en la distribución de los fondos LEADER y PRODER para el desarrollo rural, en el que el "eje del Guadalquivir" concentra las cifras más elevadas y el mayor número de municipios (Jerez, Villamartín, Marchena, Écija, Morón, Cabra, Baena, Baeza, Úbeda, etc.). Ahora bien, en lo que se refiere a las subvenciones se aprecian ciertas variaciones, ya que en este caso en el TOP 50 de municipios se incluyen algunos que no ejercen este papel de cabecera comarcal con poblaciones inferiores a los 10.000 habitantes, e incluso de los 5.000. Sin embargo, y este es el hecho que justifica las cifras obtenidas en los proyectos subvencionados, suelen ser las sedes de los GDR. Estos serían por ejemplo los casos de Cantoria (Almería), Guadahortuna y Padul (Granada), Cambil, Sabiote, o Villanueva de la Reina (Jaén), Obejo o Dos Torres (Córdoba), Yunquera, Pizarra y Molina (Málaga). 


\subsection{Los municipios con nula inversión y menor inversión}

Para entender la dinámica territorial que se generó en el periodo 2002-2008 a través de las inversiones gestionadas por los proyectos LEADER y PRODER, junto a las grandes cifras de inversión tanto por proyectos como por municipios, resulta de interés estudiar cuáles son los territorios en los que se ha invertido menos, o incluso en los que no se ha invertido nada.

La figura 8, en la que se reflejan tanto los municipios sin inversión como el TOP 50 de los que tienen menores cifras resulta muy significativo por varios motivos. En primer lugar, por el propio tamaño superficial de éstos. Como se puede observar en la figura mencionada, se trata de municipios mayoritariamente pequeños. En segundo lugar debe destacarse su localización, pues suelen situarse en zonas montañosas (precisamente las más desfavorecidas) y con más problemas estructurales de la comunidad autónoma andaluza (como son Sierra Nevada-Alpujarra, Axarquía, Serranía de Ronda, y Sierra de Aracena). En el periodo analizado y para el conjunto de Andalucía los municipios sin ninguna inversión son 51, sobre un total de 696 $(7,3 \%)$.

Figura 8. Municipios sin inversión y menor inversión de los GDR (2002-08)

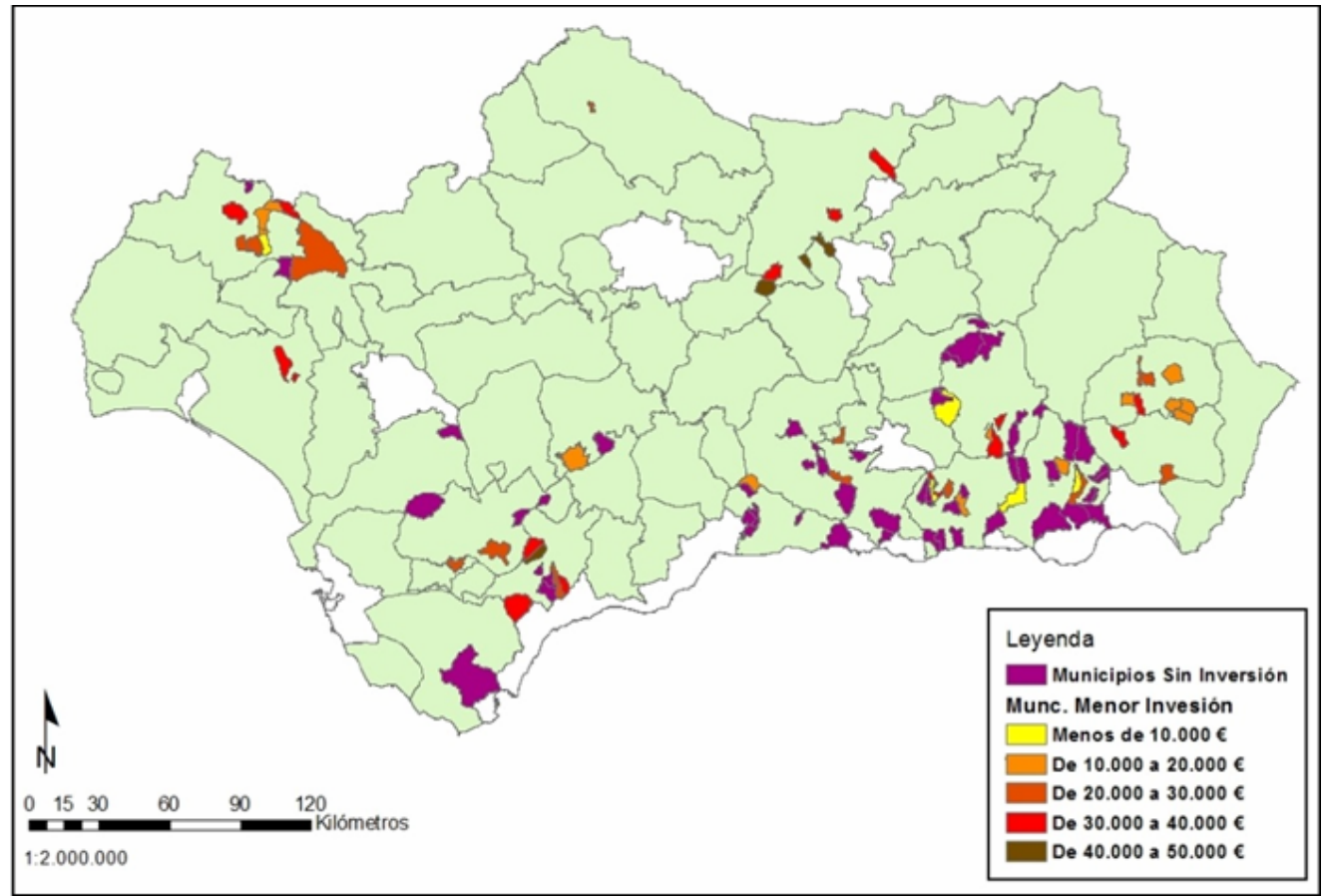

Fuente: Consejería de Agricultura, Pesca y Desarrollo Rural. Junta de Andalucía. Elaboración propia. 
Como bien señala Pita y Pedregal (2015: 52) en relación con la cohesión territorial de Andalucía, "los mayores problemas se derivan de la falta de equidad que caracteriza a determinados indicadores y variables, especialmente los de carácter económico y, más particularmente, los asociados a la competitividad. Esta es una magnitud en la que existen desequilibrios potentes en la región, una concentración de las actividades competitivas en muy escasos núcleos. Esto constituye un hecho importante a tener en cuenta en el diseño de las políticas de integración y convergencia económica".

Figura 9.Proyectos ejecutados por municipio. Andalucía (2002-08)

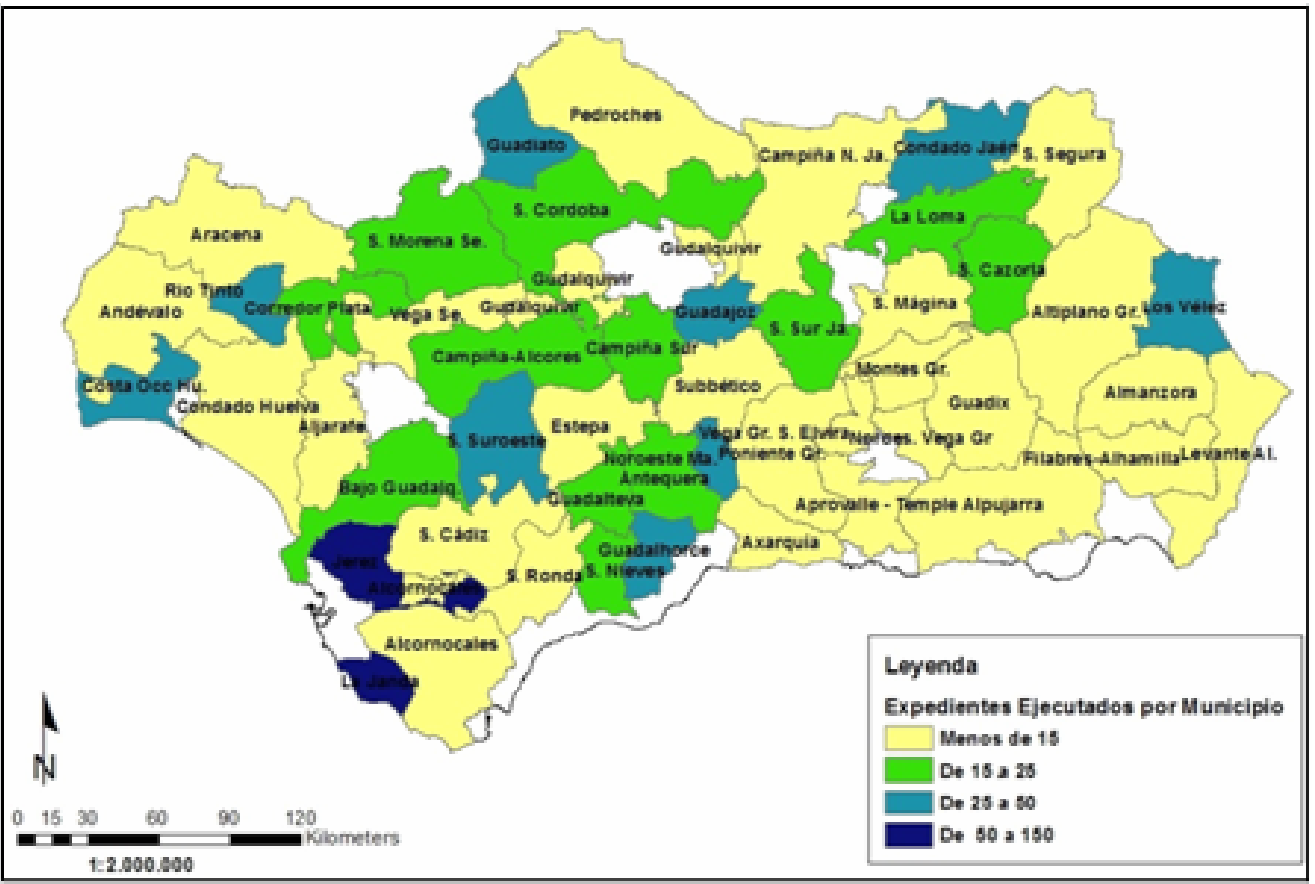

Fuente: Consejería de Agricultura, Pesca y Desarrollo Rural. Junta de Andalucía. Elaboración propia.

En cuanto a los municipios con menor inversión, son también las áreas de montaña las que concentran este tipo de situaciones. Los proyectos desarrollados en estos municipios raramente superan los $20.000 €$.

\subsection{Los proyectos ejecutados por municipios y la inversión por proyecto}

El análisis de esta variable, nuevamente nos permite apreciar claras diferencias entre los distintos GDR. Si partimos de la base de que a mayor número de proyectos ejecutados mayor dinamismo económico, no cabe duda de que son los municipios situados en lo que hemos denominado como "eje del Guadalquivir" los que presentan 
las cifras más altas. Los resultados de esta variable se pueden observar sintéticamente en la figura 9.

Los puestos superiores los ocupan La Janda y Jerez (con un solo municipio, este último, lo que distorsiona los resultados) con más de 50 proyectos ejecutados/municipio. En el escalón inferior, en el rango de los 25)50 proyectos/municipio se encontrarían otros 8 GDR (Costa Occidental y Rio Tinto en Huelva, Guadajoz y Guadiato en Córdoba, Sierra Suroriental en Sevilla, Gualdalhorce y Noroeste en Málaga, Condado en Jaén y Los Vélez en Almería).

Probablemente lo más significativo del comportamiento de esta variable sea su distribución espacial en las provincias de Granada y Almería. Si se exceptúa el caso de Los Vélez en Almería, que se justifica por el reducido número de municipios que lo integran, la media de proyectos por municipios es inferior a 15.

La inversión comprobada por proyecto, sin embargo, muestra diferencias con la figura anterior, ya que la cuantía de los proyectos no se correlaciona con la existencia de un mayor número de los mismos. No obstante, y al igual que otras variables analizadas, de nuevo se observa que los proyectos con presupuestos de inversión más elevados, de más de $200.000 €$ se localizan en los GDR situados en torno al Guadalquivir en el entorno de las ciudades de Sevilla y Córdoba (Vega de Sevilla, Guadalquivir Norte y Sur de Sevilla, Guadalquivir Medio de Córdoba). Todos estos datos se encuentran reflejados en la figura $\mathrm{n}^{\circ} 10$.

Figura 10. Inversión en euros por proyecto en los GDR de Andalucía (2002-08)

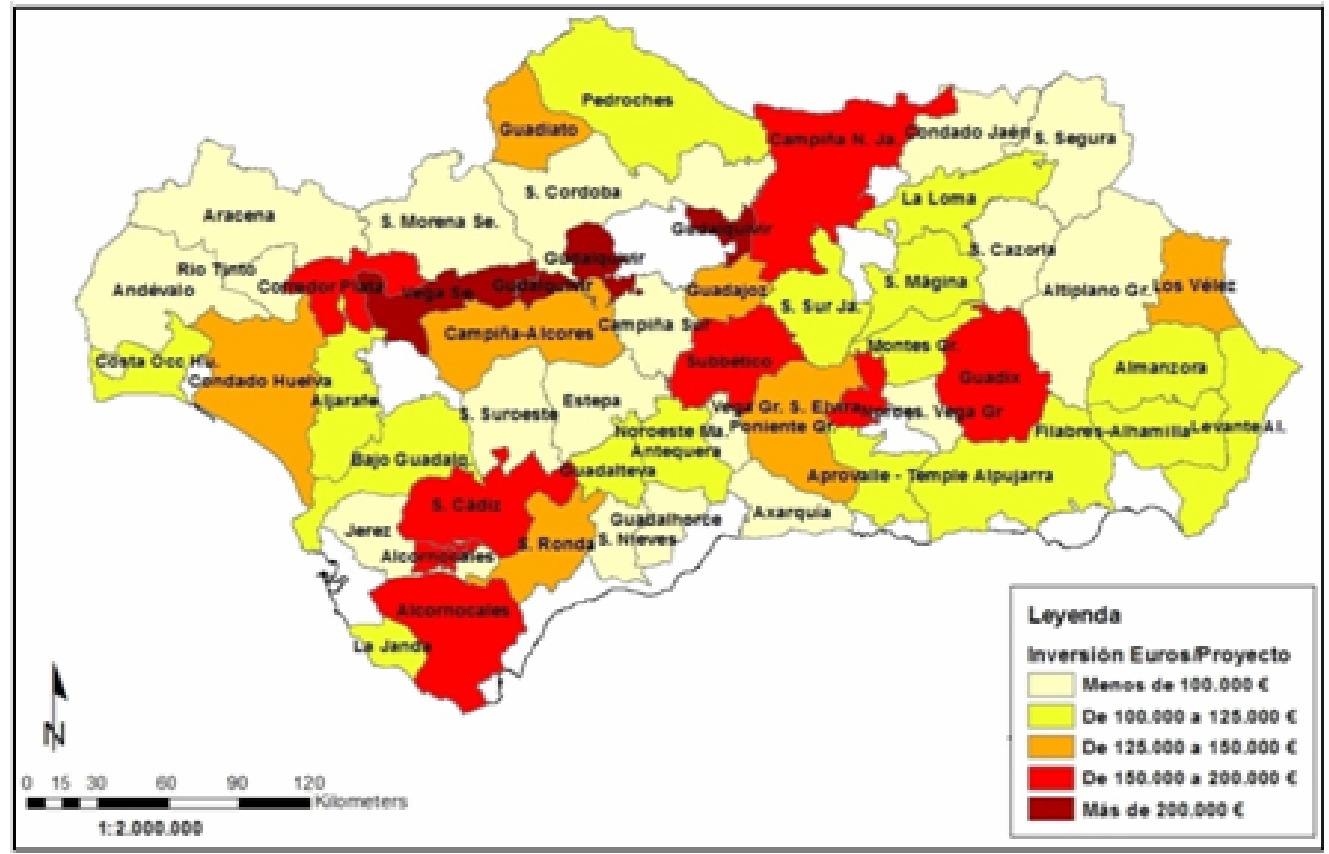

Fuente: Consejería de Agricultura, Pesca y Desarrollo Rural. Junta de Andalucía. Elaboración propia. 
Pero la cuestión es ¿qué es lo que nos demuestran estos datos? Por una parte no cabe duda, que en esta variable, al igual que en otras, se manifiesta la dualidad económica entre el sector oriental y occidental de Andalucía, ya que mientras en el primero no sólo hay un menor número de proyectos sino que también su cuantía suele ser inferior, en el segundo se concentran aquellos que tienen una mayor relevancia presupuestaría. Indirectamente nos pone de manifiesto la disparidad del tejido empresarial entre uno y otro sector. De otro lado, no cabe duda que estos valores medios se ven condicionados por la capacidad gestora de los propios GDR que son capaces de poner en marcha importantes proyectos aunque sea en base a una fuerte importancia de las subvenciones. Este es el caso de los valores resultantes en Guadix y Vega-Sierra Elvira en Granada. Un análisis pormenorizado, que aquí no se puede desarrollar, en relación con la tipología de los emprendedores de estas iniciativas se puede encontrar en Cejudo et al (2017).

\subsection{El empleo}

Los datos obtenidos de los proyectos municipalizados nos ofrecen para el conjunto de Andalucía unas cifras de 24.521 empleos, de los que un 47\% (11.606) son de nueva creación y un 53\% (12.916) de consolidación. En cuanto al comportamiento por sexos, a nivel de comunidad autónoma hay una distribución muy similar en los empleos creados con un reparto prácticamente al 50\%, que en el caso de los empleos consolidados se ve reducido para las mujeres a un 34\%. El empleo de menores de 30 años supone el $41 \%$ de los creados.

La diferenciación entre empleo creado y consolidado es importante, pues permite apreciar la repercusión social de proyectos que suponen o bien la creación de una empresa nueva o una ampliación importante de la misma en su capacidad de producción, y por tanto demandadora de mano de obra, de aquellos otros en los que la inversión realizada supone una mejora de instalaciones o sistemas de producción existentes sin generar una demanda de empleo nueva.

En la figura $n^{\circ} 11$ se han reflejado los empleos creados en el periodo 2002)2008 y de nuevo, al igual que en otras variables, se aprecia como los GDR localizados en la zonas montañosas y con menor nivel de desarrollo son las que presentan valores más bajos, generalmente inferiores a 200 empleos/GDR. En este rango se encuentran la mayor parte de los GDR de las provincias de Granada (exceptuando el entorno de la vega) y Almería en su totalidad. Serán las zonas más dinámicas de Andalucía con los GDR situados en el valle del Guadalquivir de las provincias de Córdoba y Sevilla las que presenten valores de empleo más elevados.

A modo de ejemplo baste señalar que el empleo creado en el ámbito del GDR de Guadalquivir Medio (Córdoba) supone el 12,15\% del total de Andalucía y que este valor es superior al generado en las provincias de Granada (10,62\%), Almería (6,27\%), Cádiz (7,8\%), y próximo a los totales de Jaén $(11,72 \%)$ y Málaga $(11,67 \%)$. Valores también importantes se localizan en la Costa Occidental de Huelva, Bajo Guadalquivir, Alcores y Vega de Sevilla. 
Figura 11. Empleos creados en los GDR de Andalucía (2002-08)

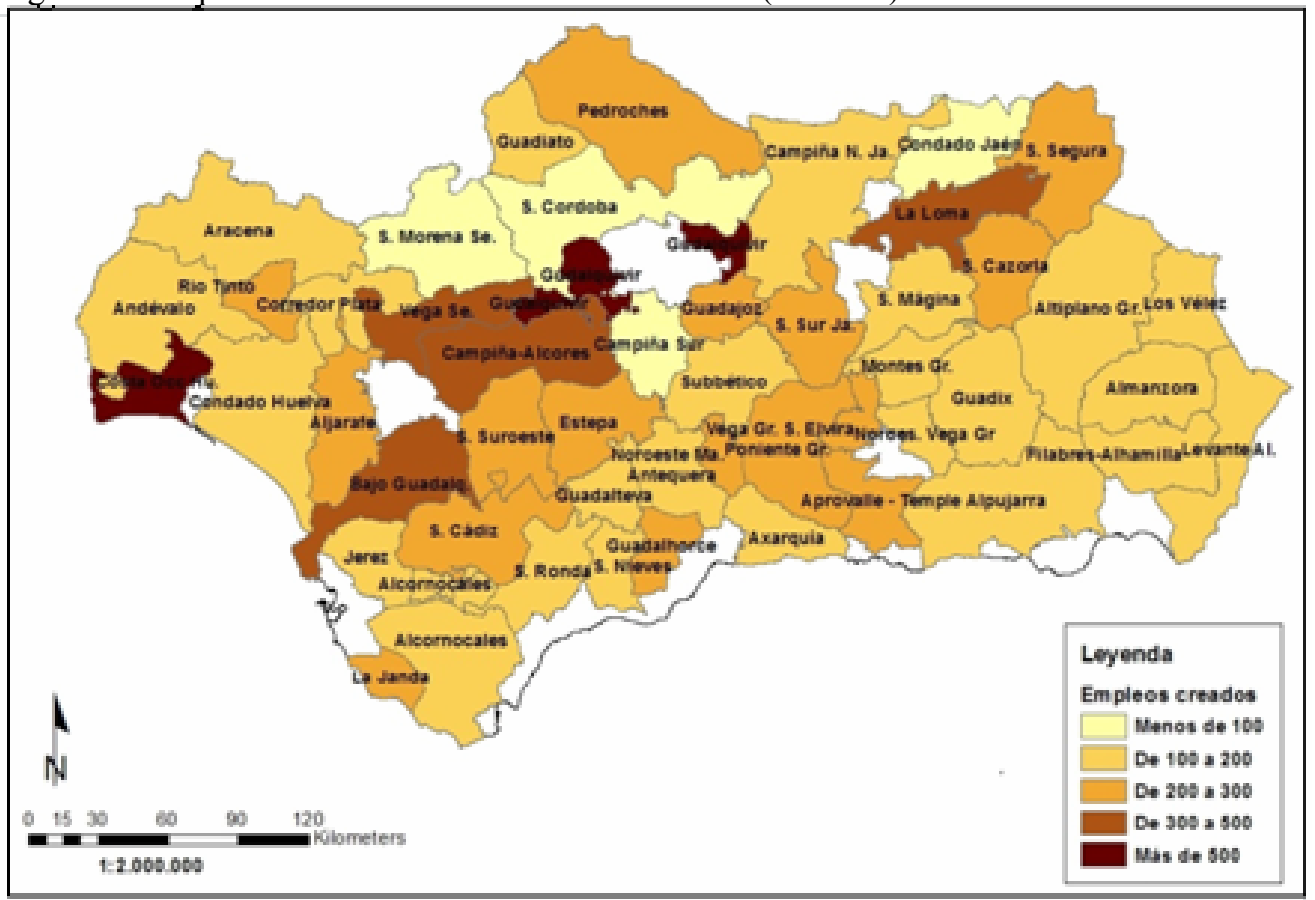

Fuente: Consejería de Agricultura, Pesca y Desarrollo Rural. Junta de Andalucía. Elaboración propia.

En lo que se refiere a los empleos consolidados los PDR han favorecido a las zonas con mayor tejido empresarial y, por tanto, con mayor dinamismo económico de Andalucía, acentuando diferencias de los espacios rurales de la comunidad. Las cifras más elevadas con más de 500 empleos consolidados se van a localizar en los GDR de las provincias occidentales (Sur de Huelva, Córdoba y Sevilla, además del arco central de la provincia de Málaga).

El contraste lo ofrecen de nuevo los GDR de las provincias de Granada y Almería, en los que destaca solamente Almanzora, en el que no se puede olvidar su potencial económico asociado a la industria del mármol (258 empleos). Las informaciones anteriores se ven complementadas con la relación entre inversión y empleo. Tal y como se puede constatar en la figura $\mathrm{n}^{\mathrm{o}} 12$ los empleos generados suelen ser más caros en las zonas rurales más profundas, con valores que se sitúan mayoritariamente entre los 50.000 y $75.000 € /$ empleo.

Los empleos generados en los GDR de las provincias de Granada y Almería suelen ser más "caros" que los localizados en el valle del Guadalquivir y sierras próximas. Es decir, "el coste" del empleo presenta los valores más elevados de Andalucía en el Condado de Jaén y Sierra de Córdoba con valores de más de $100.000 €$ de inversión/empleo. Cifras también elevadas son las de Guadix, Montes de Granada y 
Noroeste de la Vega de Granada, además de la Sierra Norte de Sevilla y La Janda, en el rango de los 75.000-100.000 €/empleo.

Figura 12. Inversión euros por empleo en los GDR de Andalucía (2002-08)

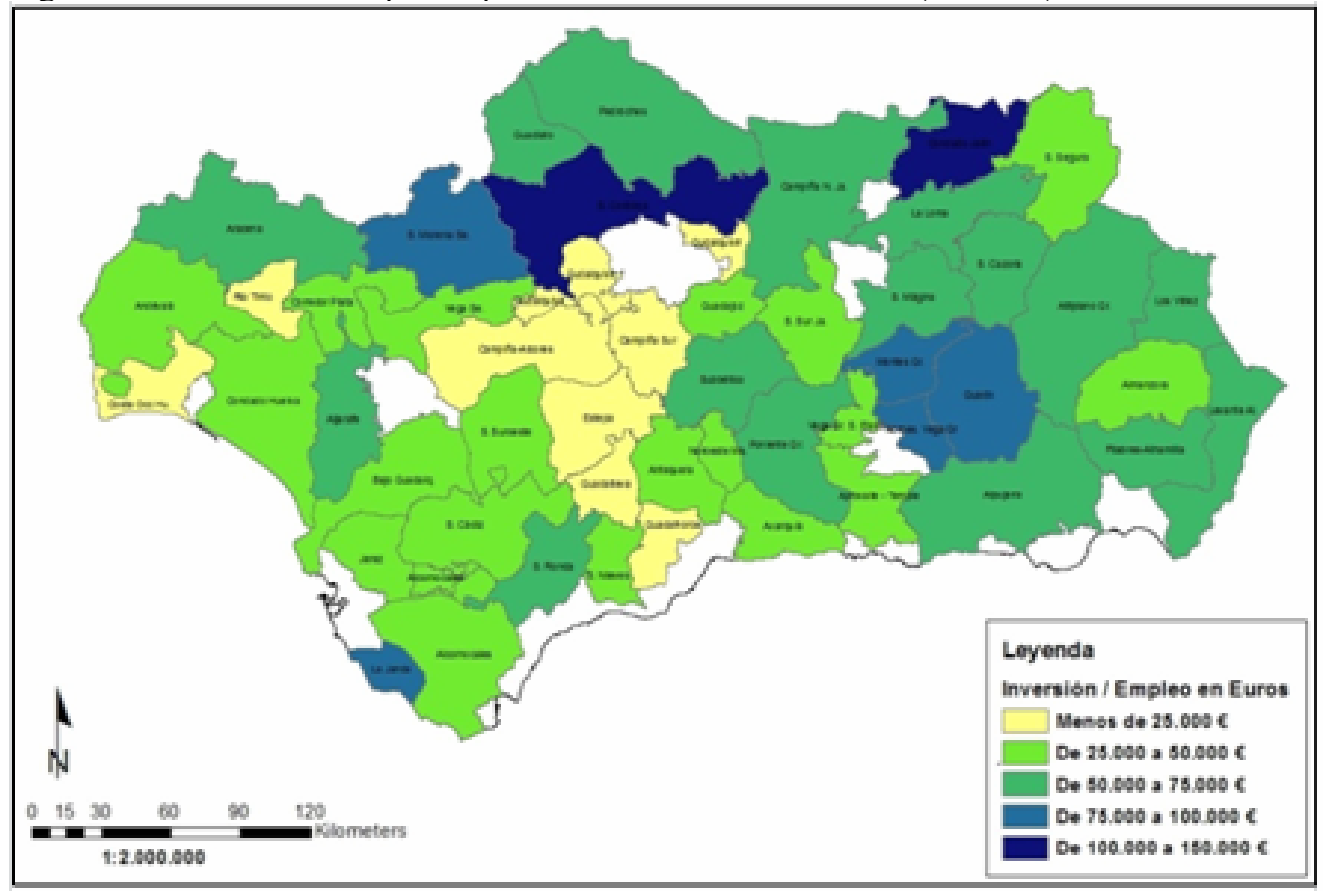

Fuente: Consejería de Agricultura, Pesca y Desarrollo Rural. Junta de Andalucía. Elaboración propia.

Así pues, en las zonas rurales más profundas no sólo el empleo generado tiene un coste mayor, sino que también depende más de las subvenciones asociadas a los proyectos.

\subsection{La confirmación de nuestra hipótesis}

Todo lo analizado hasta ahora también se ve respaldado si se estudia el reparto de la inversión por intervalos de población municipal (cuadro $\mathrm{n}^{\circ} 3$ ), donde mientras que los municipios situados entre 0-999 habitantes apenas acogieron un 5,3\% del total de la inversión, los comprendidos entre 2.000 y 20.000 y más, acapararon un $85,7 \%$. Es decir, el rural profundo quedó, de forma considerable, al margen de las iniciativas de los programas de desarrollo rural. Incluso la aportación pública contribuyó a reforzar la concentración territorial, ya que acompañó ligeramente más $(68,1$ sobre $100 €)$ en los municipios de más de 20.000 habitantes, frente a los 64,3 en los municipios de 0 999 habitantes. En otras variables como el empleo creado para mujeres y empleo creado total, también se aprecian esas dicotomías. 
Cuadro 3. Reparto de la inversión y empleos creados de LEADER/PRODER en Andalucía en el periodo 2002-2008 por intervalos de población municipal.

\begin{tabular}{|c|c|c|c|c|c|c|c|c|c|}
\hline Intervilos & N mine. & Follacion & $\begin{array}{l}\text { heessián } \\
\text { thil }\end{array}$ & \% Inersián & $\begin{array}{c}\text { Pelac } \\
\text { insersián } \\
\text { Fivalattatil }\end{array}$ & $\begin{array}{c}\text { Fipleo } \\
\text { arado } \\
\text { nujeres }\end{array}$ & 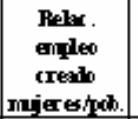 & $\begin{array}{l}\text { Enpleos } \\
\text { cealiss }\end{array}$ & 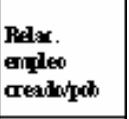 \\
\hline $0-499$ & 96 & 30.96 & 13201501 & 15 & 649 & 50 & \begin{tabular}{|l|}
0,16 \\
\end{tabular} & 101 & 033 \\
\hline $500-999$ & 92 & 66.900 & 32.714230 & 3.8 & 63,7 & 117 & 0,18 & 278 & 0,42 \\
\hline $1000-1999$ & 116 & 166.88 & 78.634394 & 9,1 & 633 & 201 & 0,16 & $+\infty 0$ & 0,41 \\
\hline $2000-4999$ & 196 & 613.175 & 245952048 & 285 & 645 & 1.400 & 0,2 & 2843 & 0,46 \\
\hline $5000-9999$ & 99 & 674645 & 10596632 & 22,7 & 64,7 & 1210 & 0,18 & $25 m$ & 0,3 \\
\hline 10000-19999 & 9 & 2460006 & 144998020 & 168 & 673 & 1209 & 0,15 & 2625 & 0,31 \\
\hline $20000 y+$ & 3 & 1204845 & 152992.756 & 17,7 & 68,1 & 1046 & 0,08 & 2.168 & 0,17 \\
\hline Tat: & 696 & 3.02901 & $\$ 64249272$ & 100 & 655 & 5375 & 0,15 & 11282 & 0,31 \\
\hline
\end{tabular}

Fuente: Consejería de Agricultura, Pesca y Desarrollo Rural. Junta de Andalucía. Elaboración propia.

Cuadro 4. Correlaciones en los diferentes GDR base al IRPF, IAE y el Índicede Dependencia en relación con la inversión total y privada

\begin{tabular}{|c|c|c|c|c|c|c|}
\hline $\operatorname{Gog}$ & 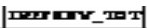 & |rexnory & 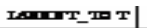 & IACIITIIIX & TKar_tat | & rmoryer \\
\hline 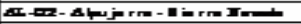 & 0.430 & 0396 & 0.483 & 0446 & -0.191 & -0.194 \\
\hline EADA-Mintrie & 0.021 & 0657 & 0.003 & 0640 & -0378 & -0378 \\
\hline 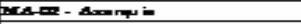 & 0.181 & 0209 & 0.238 & 0266 & -0.130 & -0.135 \\
\hline 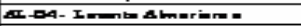 & 0.160 & 0.170 & 0251 & 0276 & -0.312 & -0314 \\
\hline 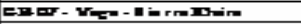 & 0318 & 0285 & 0.436 & 0,408 & -0.153 & -0.137 \\
\hline 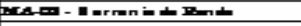 & 0.091 & 0089 & 0.089 & 0087 & -0203 & -0.299 \\
\hline 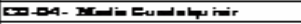 & 0.553 & $0 \leq 58$ & 0 s17 & $0 \leq 54$ & -0.405 & -0.420 \\
\hline 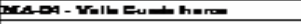 & 0,743 & 0,799 & 0,578 & 0,628 & $-0,149$ & $-0,118$ \\
\hline 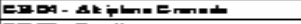 & 0.839 & 0.843 & 0.820 & 0.825 & -0.451 & -0.466 \\
\hline 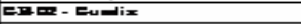 & 0.83 & 0.801 & 0.88 & 0809 & -0339 & -0350 \\
\hline 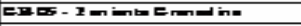 & 0.892 & 0821 & 0.871 & $0.7 \%$ & -0320 & -0300 \\
\hline 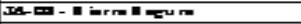 & 0,197 & 0,138 & 0,200 & 0,184 & $-0,280$ & $-0,235$ \\
\hline 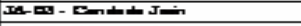 & 0,370 & 0,414 & $0,57 S$ & 0,580 & $-0,300$ & $-0,280$ \\
\hline 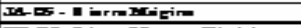 & D.249 & 0209 & 0.201 & 0223 & -0.039 & $-0,089$ \\
\hline 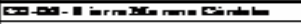 & 0.713 & 0.752 & 0.799 & 0809 & -0.484 & -02243 \\
\hline Ex-E- IDrdim: & 0.514 & $0 \leq 78$ & 0.035 & 0,080 & -0.669 & -0.059 \\
\hline EA & -0.098 & $-0,003$ & -0.809 & -0.751 & 0.788 & 0731 \\
\hline 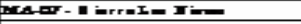 & 0274 & 0.12 & $0 \geq 82$ & 0224 & -0.138 & 0085 \\
\hline 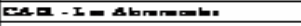 & -0.203 & -0.103 & -0.178 & -0.140 & 0.167 & 0.129 \\
\hline 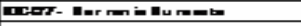 & 0.869 & 0028 & 0.88 & 0002 & -0.498 & $-0,492$ \\
\hline 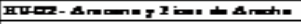 & 0.031 & 0020 & 0.030 & 0028 & -0.180 & -0.180 \\
\hline 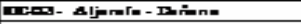 & 0358 & 0310 & 0.002 & $0 \leq 17$ & -0.111 & -0.113 \\
\hline 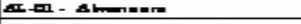 & 0.473 & 0.494 & 0.483 & 0.499 & -0.278 & -0207 \\
\hline 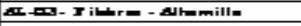 & 0.829 & 0.751 & 0.843 & Q.781 & -0.444 & $-0,441$ \\
\hline 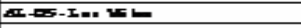 & 0.85 & 0839 & 0.843 & 0816 & -0.461 & -0415 \\
\hline 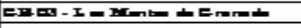 & 0.60 & 0933 & 0.ss & 0921 & $-0,032$ & -0.576 \\
\hline 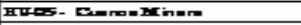 & 0,801 & 0,896 & 0,738 & 0,807 & $-0, \sqrt{34}$ & $-0,578$ \\
\hline 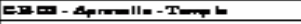 & 0.857 & 0.820 & 0909 & 0879 & -0.479 & -0.486 \\
\hline 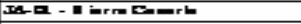 & 0,034 & 0,461 & 0,029 & 0,444 & $-0,407$ & $-0,407$ \\
\hline 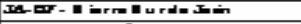 & 0,397 & 0,405 & 0,559 & 0,509 & 0,189 & 0,162 \\
\hline 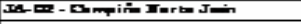 & 0,397 & 0,405 & 0.559 & 0,500 & 0,189 & 0,162 \\
\hline 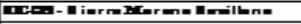 & 0,032 & 0,608 & 0,578 & 0,618 & $-0,333$ & $-0,404$ \\
\hline 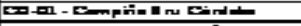 & 0.009 & 0.572 & 0.768 & 0.654 & -0.189 & -0300 \\
\hline 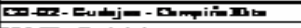 & 0.990 & 0089 & 0.994 & 0993 & -0.744 & -0.731 \\
\hline Marr-Eutbl & 0.002 & 0608 & o_sf? & 0.618 & $-0,333$ & $-0,404$ \\
\hline axa - Anburum & 0.334 & 0337 & 0.338 & 0339 & -0.409 & -0.410 \\
\hline 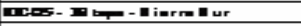 & 0.654 & $0 \leq 5$ & 0.087 & 0,000 & -0.297 & -0.255 \\
\hline 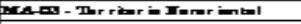 & 0.059 & 0059 & 0.002 & 0.890 & -0.499 & -0.498 \\
\hline EAm - Jar- & st & sa & st & sa & sed & st \\
\hline 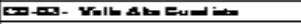 & 0.783 & 0820 & 0.857 & 0885 & $-0,28$ & $-0 \leq 88$ \\
\hline 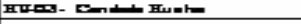 & 0.523 & $0 \leq 31$ & 0.373 & 0380 & $-0,387$ & -0376 \\
\hline 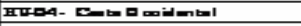 & -0.165 & -0.173 & -0241 & -0241 & $-0,074$ & $-000 \mathrm{~g}$ \\
\hline 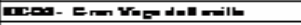 & 0343 & 0343 & $0 \approx 81$ & 0277 & -0.294 & -0.572 \\
\hline 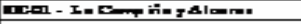 & 0.263 & 0765 & 0.801 & 0708 & -0.210 & -0.154 \\
\hline 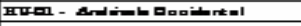 & 0.822 & 088s & 0.80 & $08 \pi 7$ & -0314 & -0325 \\
\hline 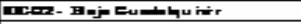 & 0,003 & $0,0,8$ & 0,008 & 0,093 & $-0,328$ & $-0,349$ \\
\hline 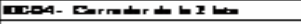 & 0,770 & 0,767 & 0,805 & 0,805 & $-0,399$ & $-0,400$ \\
\hline 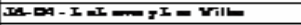 & 0.858 & 0,885 & 0,800 & 0,880 & $-0,316$ & $-0,399$ \\
\hline 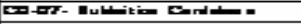 & 0,000 & 0,695 & 0.032 & 0,639 & $-0,338$ & $-0,334$ \\
\hline 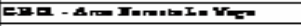 & $0 \leq 68$ & 0.609 & 0.713 & 0.761 & $-0 \leq 42$ & $-0 \leq 79$ \\
\hline TOTAL & 0,452 & 0,426 & 0,502 & 0,482 & $-0,18$ I & $-0,177$ \\
\hline
\end{tabular}

Fuente: Instituto de Estadística y Cartografía de Andalucía. Elaboración propia. 
Y para refrendar lo anteriormente señalado, se puede apreciar que en el cuadro $\mathrm{n}^{\circ}$ 4 las correlaciones entre renta per cápita, impuesto de actividad económica e índice de dependencia demográfico con la inversión total y privada, de los PDR en el periodo 2002-2008, muestran la concentración y reparto de las inversiones atendiendo a estos indicadores: riqueza económica $(0,45)$, presencia de tejido empresarial $(0,50)$, y aunque en menor número de GDR con la dependencia poblacional.

En este sentido resaltar muy especialmente que para la correlación entre renta per cápita e inversión total, 21 GDR (41\%) presentan una asociación elevada (por encima de 0,70$), 13$ de éstos (25\%), una asociación de tipo medio (entre 0,40 y 0,70 ), y solo en uno de ellos $(2 \%)$ la situación es inversa.

\section{Conclusiones}

Las regiones del sur de Europa se han considerado tradicionalmente como espacios con una economía básicamente agraria en la que los problemas de despoblamiento y envejecimiento de sus efectivos están poniendo en duda la viabilidad económica y social de amplios territorios. Invertir en ellos, dotándolos de equipamientos y servicios que otorguen a sus habitantes una calidad de vida mínima, no es sólo de justicia social, equiparando sus derechos a los de los residentes en las zonas urbanas, sino también una necesidad económica y ambiental para evitar su degradación territorial.

Dentro de su reducido presupuesto, LEADER y PRODER se configuraron como instrumentos emblemáticos de intervención directa en estos espacios para favorecer la diversificación económica e incentivar su dinamismo. El periodo analizado 20022008 se puede considerar como una etapa de madurez en este tipo de políticas. El análisis efectuado permite mantener que, tal y como se han llevado a cabo, han acentuado los desequilibrios territoriales preexistentes en Andalucía. Se puede afirmar, sin género de duda, que son aquellos territorios más dinámicos, situados en el entorno a las zonas metropolitanas los que se han visto especialmente favorecidos, mientras las áreas de montaña, con economías básicamente agrarias y escasamente pobladas, además de envejecidas, son las que presentan índices de inversión menores.

El reparto territorial de los PDR ha sido muy desigual, apreciándose no sólo un número mayor de proyectos ejecutados sino también de la inversión realizada en los municipios del sector occidental de Andalucía, y más concretamente en torno al Valle del Guadalquivir. Salvo contadas excepciones, los proyectos con mayor inversión son aquellos en los que la inversión privada ha sido más importante, siendo más reducida la incidencia de las subvenciones. Lo que confirma la correlación existente entre mayor número de proyectos con la preexistencia de un cierto tejido empresarial.

De igual modo, los proyectos con mayor inversión privada se han destinado en su mayor parte a sectores relacionados con la hostelería-restauración. Las inversiones en el tejido industrial son escasamente representativas, siendo en su mayor parte mejoras de empresas que ya existían y raramente de nueva creación. Son sociedades 
mercantiles (anónimas o limitadas) las que ejercen el liderazgo, con una reducida presencia de autónomos.

No cabe duda, que la preexistencia de una capacidad financiera previa se constituye en un elemento esencial para entender la ejecución de los proyectos. De esta forma el acceso a las subvenciones de los PDR no son más que un "extra" en la financiación que, en cualquier caso, no es esencial para la viabilidad del proyecto, pues se habría llevado a cabo en su ausencia.

El empleo generado es, siempre, muy escaso, siendo sus costes muy variables. El coste de "creación" de empleo es muy variable, siendo en términos económicos más barato en las zonas más desarrolladas y con mayor presencia financiera de la inversión privada que en las zonas más desfavorecidas, donde se encarece considerablemente, además de ser numéricamente menor.

Por otro lado y aunque los proyectos subvencionados asumen funciones de reequipamiento territorial en zonas y ámbitos donde otras administraciones no llegan a asumir sus competencias, mejorando la calidad de vida sus habitantes, su incidencia territorial es muy variable. Los proyectos con mayor cuantía recibida se localizan, también, de forma mayoritaria en los GDR del occidente andaluz, siendo en las provincias de Granada y Almería donde se detectará, por su parte, una cierta concentración de municipios de "no inversión".

Las inversiones se concentran, así, en los municipios de mayor tamaño demográfico, renta per cápita y presencia empresarial, y al contrario, son minoritarias en los municipios con menor población, renta per cápita y presencia empresarial. Es decir, las bases en las que se han sustentado estas iniciativas han sido insuficientes para evitar que los desequilibrios se acentúen, reforzándose a los territorios rurales dinámicos frente a los menos emprendedores, en definitiva, perdedores.

La subvención en proyectos, tal y como se ha llevado a cabo, no es suficiente si no se ancla a iniciativas empresariales, lo cual es difícil cuando los habitantes de estas zonas no forman parte de este tejido, están envejecidos o su formación es escasa. Romper esa dinámica se constituye en esencial si se quiere que los futuros programas tengan un éxito mayor.

Algunos autores que han abordado la evaluación de la eficacia de estas iniciativas (Esparcia y Escribano, 2012; GATER, 2015) señalan la participación de los habitantes de la zona como esencial en el diseño de las estrategias a llevar a cabo y en la priorización de los sectores en los que invertir. Se habla de una participación efectiva y no formal, "audiencia pública", que no conduce a nada. La implicación de los habitantes se constituye, así, en esencial. Los planteamientos parecen lógicos en teoría, pero lo complicado es como se llevan a cabo en espacios con índices de desarrollo tan bajos y con escasa población. 


\section{Bibliografía}

Alario, M. y Baraja, E. (2006): Políticas públicas de desarrollo rural en Castilla y León, ¿sostenibilidad consciente o falta de opciones?: Leader II. Boletín de la Asociación de Geógrafos Españoles, 41, 267-293.

Arcila, M. y López, J.A. (2015): Los centros de interpretación como motor de desarrollo turístico local, ¿un modelo fracasado? El caso de la provincia de Cádiz. Boletín de la Asociación de Geógrafos Españoles, 67, 143-165.

Augustyn, A. y Nemes, G. (2014): Catching up with the West? Europeanisation of rural policies in Hungary and Poland, Studies in agricultural economies, 116, 114-121.

Böcher, M. (2008): Regional governance and rural development in Germany: the implementation of LEADER +, Sociologia Ruralis, 48(4), 372-388.

Bosworth, G. Annibal, I. Carroll, T., Price, L., Sellick, J. y Shepherd, J. (2016): Empowering local action through neo)endogenous development; the case of LEADER in England, Sociologia Ruralis, 56(3), .427-449.

Buciega, A. (2012): Capital social y LEADER. Los recursos generados entre 1996 y 2006, Ager, 12, pp. 111-144.

Camarero, L. (Coord.) (2009): La población rural de España. De los desequilibrios a la sostenibilidad social. Colección Estudios Sociales, $n^{\circ} 27$. Barcelona, La Caixa.

Caravaca, I. y Otros. (2013): Economía creativa en la aglomeración metropolitana de Sevilla: agentes, redes locales de colaboración y principales actuaciones. Boletín de la Asociación de Geógrafos Españoles, 63, 81-103.

Casellas, A. y Otros. (2013): Gobernanza local y espacio rural: un análisis territorial desde la perspectiva de género. Boletín de la Asociación de Geógrafos Españoles, 62, 379-402.

Cejudo, E. y Navarro, F. (2009): La inversión en los programas de desarrollo rural. Su reparto en la provincia de Granada. Anales de Geografía de la Universidad Complutense, vol. 29 (2), 37-64.

Cejudo, E. y Navarro, F. (2012): Quince años de aplicación de los Programas de Desarrollo Rural. Desigualdades sociales y territoriales en la provincia de Granada, Scripta Nova, XVI(390). www.ub.edu_geocrit_sn_sn-390.pdf

Cejudo, E., Navarro, F. y Cañete, J.A. (2016): Evolución y distribución territorial de los trabajadores eventuales agrarios subsidiados en Andalucía, Boletín de la Asociación de Geógrafos Españoles, 72, 117-147.

Cejudo, E. Navarro, F. y Camacho, J.A. (2017): Perfil y características de los beneficiarios finales de los Programas de Desarrollo Rural en Andalucía. LEADER+ y PRODER2 (2000-2006). Cuadernos Geográficos, (en prensa).

Cheshire, L., Esparcia, J. y Shucksmith, M. (2015): Community resilience, social capital and territorial governance, Ager, 7-38.

Dargan, L. y Shucksmith, M. (2008): Leader and innovation, Sociologia Ruralis, 48(3), 274291.

De Rubertis, S., Belliggiano, A. (2016) El "farm tourism" como oportunidad de desarrollo sostenible en las regiones del sur de Italia. PAMPA, 13(1er. Semestre), 11-30.

Esparcia, J. (2014). Innovatión and networsks in rural areas. An analysis from European innovative proyects. Journal of Rural Esudies, 43, 1-14 
Esparcia, J. y Escribano, J. (2012): La dimensión territorial en la programación comunitaria y el nuevo marco de políticas públicas: desarrollo rural territorial, reforma de la PAC y nuevo LEADER, Anales de Geografía, 32(2), 227-252.

Fernández, J. (2011): Distribución y difusión espacio-temporal de la política de desarrollo rural en Castilla y León: de la Iniciativa LEADER I al LEADERCAL (1991-2013), Cuadernos de Geografía, 89, 49-70.

Gardner, G. (2011): Community action in rural Wales, en P. Milbourne (ed.), Rural Wales in the twenty-first century. Society, economy and environment, Cardiff, University of Wales, 81-112.

Gordo, P. (2011): Las políticas territoriales de desarrollo rural de la Unión Europea, Estudios de Economía Aplicada, 29(1), 7-30.

Grupo De Análisis Sobre Territorios Rurales (GATER) (2015): Hacia nuevas políticas de desarrollo territorial en las áreas rurales de la Comunidad Valenciana: Iniciativas territoriales y servicios públicos en J. Romero y A.Boix (ed), Democracia desde abajo. Nueva Agenda para el Desarrollo Local. Estudios y Documentos $n^{\circ} 17$. Universidad de Valencia. 355-382.

Gujoan, E., Badía, A. y Tulla, F. (2016): El nuevo paradigma del desarrollo rural. Reflexión teórica y reconceptualización a partir del Rural Web. Boletín de la Asociación de Geógrafos Españoles, 71, 179-2014

Hortelano, L.A. y Martín, M. I. (1999): La incidencia de las iniciativas comunitarias y de los fondos europeos en el desarrollo rural de la provincia de Salamanca, Polígonos, 53-86.

Junta de Andalucía. (2013): Programa de Desarrollo Rural de Andalucía 2014)2020. Consejería de Agricultura, Pesca y Desarrollo Rural, Sevilla.

Llorente, J.M. y Martín, M.I. (2010): Percepción de las experiencias de cooperación y gobierno del territorio en zonas de baja densidad, Cuadernos de Geografía, 88, 241-258.

Labianca, M., De Rubertis, S., Belliggiano, A. y Salento, A. (2016): Innovation in rural development in Puglia, Italy: critical issues and potentialities starting from empirical evidence. Studies in Agricultural Economics, 118, 38-46.

Márquez, D. y Otros. (2006): El precio de la sostenibilidad rural en Andalucía: el valor de LEADER II Boletín de la Asociación de Geógrafos Españoles, 41, 295-313.

Marsden, T. (2009) Mobilities, vulnerabilities and sustainabilities. Sociologia Ruralis, 49(2), 113-131.

Martínez, F., Sacristán, H. y Yagüe, J.L. (2015): Are local action groups, under LEADER approach, a good way to support resilience in rural areas? Ager, 18, 39-63.

Ministerio de Medio Ambiente y Medio Rural y Marino (2011): Diagnóstico de la Igualdad de Género en el Medio Rural, Madrid.

Ministerio De Medio Ambiente Y Medio Rural y Marino (2012). LEADER en España (1991)2011). Una contribución activa al desarrollo rural. Madrid.

Nardone, G., Sisto, R. y Lopolito, A. (2010): Social capital in the Leader Initiative: a methodological approach, Journal of Rural Studies, 26, 63-72.

Navarro, F., Cejudo, E. y Maroto, J. (2014): Reflexiones en torno a la participación en el desarrollo rural. ¿Reparto social o reforzamiento del poder? LEADER y PRODER en el sur de España, Eure, 40(121), 203-224. 
Navarro, F., Woods, M. y Cejudo, E. (2016). The LEADER Initiative has been a victim of its own success. The decline of the bottom-up approach in rural development programmes. The cases of Wales and Andalusia, Sociologia Ruralis, 56(2), 270-288.

Navarro, S. y Larrubia, R. (2000). Los programas LEADER II en la provincia de Málaga. Su contribución al desarrollo del espacio rural, Baética, 22, 109-146.

Nieto, A. y Gurría, J. L. (2005): Análisis de la población de los programas de desarrollo rural en Extremadura mediante SIG, Cuadernos Geográficos, 36, 479-495.

Observatorio Europeo Leader/Aidl (2001). Guía pedagógica del planteamiento LEADER. Dirección General de Agricultura de la Unión Europea. Bruselas.

Osti, G. (2000): Leader and partnerships: the case of Italy, Sociologia Ruralis, 40(2), 172-180.

Plaza, J.I. (2006): Territorio, geografía rural y políticas públicas. Desarrollo y sustentabilidad en las áreas rurales, Boletín de la Asociación de Geógrafos Españoles, 41, 69-95.

Pillet, F. y Santos, J.F. (2008): Balance de las etapas del desarrollo rural territorial en CastillaLa Mancha: la necesaria política comarcal en Las agriculturas españolas y la Política Agraria Comunitaria: 20 años después. Actas del XIII Coloquio de Geografía Rural. (Araque Jiménez, E. et al., coords.) Baeza: Universidad Internacional de Andalucía, 605620.

Pita, M.F. y Pedregal, B. (2015): La medición de la cohesión territorial a escala regional. Propuesta metodológica y aplicación a Andalucía. Boletín de la Asociación de Geógrafos Españoles, 68, 31-55.

Porto, A.M. y Otras (2015): Formación de las mujeres, empoderamiento e innovación rural. Boletín de la Asociación de Geógrafos Españoles, 68, 385-406.

Ray, C. (2006): Neoendogenous rural development in the EU. 278)290 en P. Cloke, T. MARSDEN y P.H. MOONEY (eds.), Handbook of rural studies, London: Sage.

Rodríguez, F. (2001): Las montañas andaluzas en la encrucijada del desarrollo rural, Eria, 54$55,125-139$.

Sánchez, P., Gallardo, R. y Ceña, F. (2014): Rural areas face the economic crisis: analysing the determinants of successful territorial dynamics, Journal of Rural Studies, 35, 11-25.

Saraceno, E. (2013): Disparity and diversity: their use in EU rural policies, Sociologia Ruralis, 53(3), 331-348.

Shortall, S. (2008): Are rural development programmes socially inclusive? Social inclusion, civic engagement, participation, and social capital: exploring the differences, Journal of Rural Studies, 24, 450-457.

Toledano, N. y Gessa, A. (2002): El turismo rural en la provincia de Huelva. Un análisis de las nuevas iniciativas creadas al amparo de los programas LEADER II y PRODER, Revista de Desarrollo Rural y Cooperativismo Agrario, 6, 107-121.

\section{Normativa}

Reglamento (UE) n ${ }^{\circ}$ 1303/2013 del Parlamento Europea y del Consejo de 17 de diciembre de 2013 por el que se establecen disposiciones comunes relativas al Fondo Europeo de Desarrollo Regional, al Fondo Social Europeo, al Fondo de Cohesión, al Fondo Europeo 
Agrícola de Desarrollo Rural y al Fondo Europeo Marítimo y de la Pesca, y por el que se establecen disposiciones generales relativas al Fondo Europeo de Desarrollo Regional, al Fondo Social Europeo, al Fondo de Cohesión y al Fondo Europeo Marítimo y de la Pesca, y se deroga el Reglamento (CE) no 1083/2006 del Consejo. 